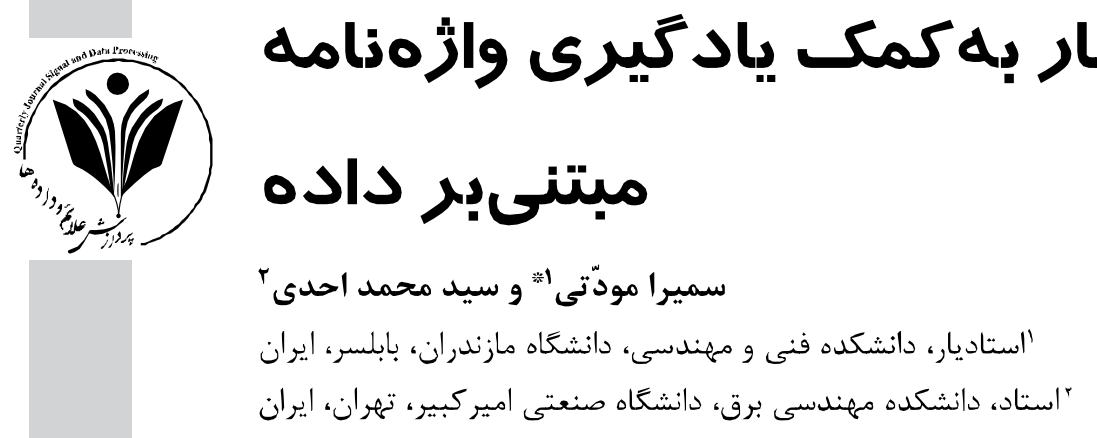

جكکبه

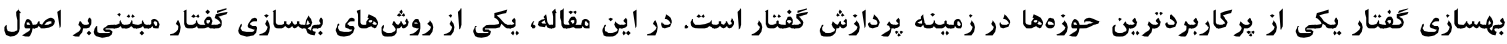

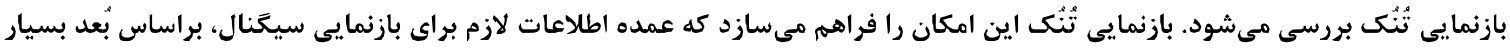

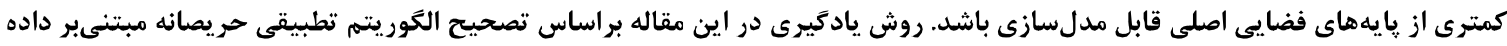

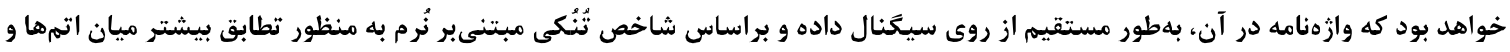

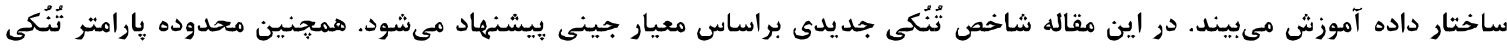

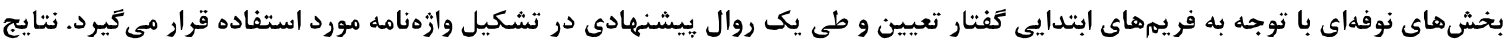

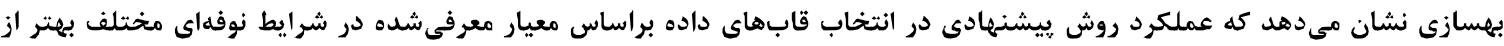

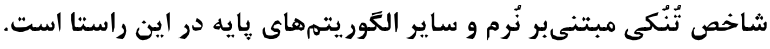

وازَّان كليدى: بهسازى كَفتار، بازنمايى تُنُك، يادَّيرى وازٔهامه، مبتنىبر داده، تطبيقى حريصانه، شاخص تُنُكى جينى

\title{
Speech Enhancement using Adaptive Data-Based Dictionary Learning
}

\author{
Samira Mavaddati ${ }^{*}$ \& Seyyed Mohammad Ahadi ${ }^{2}$ \\ ${ }^{1}$ Electrical Department, Faculty of Technology and Engineering, University of Mazandaran, \\ Babolsar, Iran \\ ${ }^{2}$ Electrical Engineering Department, Amirkabir University of Technology, Tehran, Iran
}

\begin{abstract}
In this paper, a speech enhancement method based on sparse representation of data frames has been presented. Speech enhancement is one of the most applicable areas in different signal processing fields. The objective of a speech enhancement system is improvement of either intelligibility or quality of the speech signals. This process is carried out using the speech signal processing techniques to attenuate the background noise without causing any distortion in the speech signal. In this paper, we focus on the single channel speech enhancement corrupted by the additive Gaussian noise. In recent years, there has been an increasing interest in employing sparse representation techniques for speech enhancement. Sparse representation technique makes it possible to show the major information about the speech signal based on a smaller dimension of the original spatial bases. The capability of a sparse decomposition method depends on the learned dictionary and matching between the dictionary atoms and the signal features. An over complete dictionary is yielded based on two main steps: dictionary learning process and sparse coding technique. In dictionary selection step, a pre-defined dictionary such as the Fourier basis, wavelet basis or discrete cosine basis is employed. Also, a redundant dictionary can be constructed after a learning process

* Corresponding author

* نويسندة عهدهدار مكاتبات
\end{abstract}

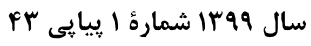

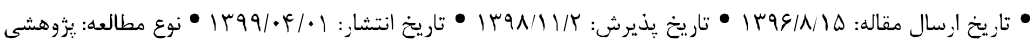


that is often based on the alternating optimization strategies. In sparse coding step, the dictionary is fixed and a sparse coefficient matrix with the low approximation error has been earned. The goal of this paper is to investigate the role of data-based dictionary learning technique in the speech enhancement process in the presence of white Gaussian noise. The dictionary learning method in this paper is based on the greedy adaptive algorithm as a data-based technique for dictionary learning. The dictionary atoms are learned using the proposed algorithm according to the data frames taken from the speech signals, so the atoms contain the structure of the input frames. The atoms in this approach are learned directly from the training data using the norm-based sparsity measure to earn more matching between the data frames and the dictionary atoms. The proposed sparsity measure in this paper is based on Gini parameter. We present a new sparsity index using Gini coefficients in the greedy adaptive dictionary learning algorithm. These coefficients are set to find the atoms with more sparsity in the comparison with the other sparsity indices defined based on the norm of speech frames. The proposed learning method iteratively extracts the speech frames with minimum sparsity index according to the mentioned measures and adds the extracted atoms to the dictionary matrix. Also, the range of the sparsity parameter is selected based on the initial silent frames of speech signal in order to make a desired dictionary. It means that a speceh frame of input data matrix can add to the first columns of the over complete dictionary when it has not a similar structure with the noise frames. The data-based dictionary learning process makes the algorithm faster than the other dictionary learning methods for example K-singular value decomposition (K-SVD), method of optimal directions (MOD) and other optimization-based strategies. The sparsity of an input frame is measured using Ginibased index that includes smaller measured values for speech frames because of their sparse content. On the other hand, high values of this parameter can be yielded for a frame involved the Gaussian noise structure. The performance of the proposed method is evaluated using different measures such as improvement in signal-to-noise ratio (ISNR), the time-frequency representation of atoms and PESQ scores. The proposed approach results in a significant reduction of the background noise in comparison with other dictionary learning methods such as principal component analysis (PCA) and the norm-based learning method that are traditional procedures in this context. We have found good results about the reconstruction error in the signal approximations for the proposed speech enhancement method. Also, the proposed approach leads to the proper computation time that is a prominent factor in dictionary learning methods.

Keywords: Speech enhancement, Sparse representation, Dictionary learning, Data-Based learning, Greedy adaptive

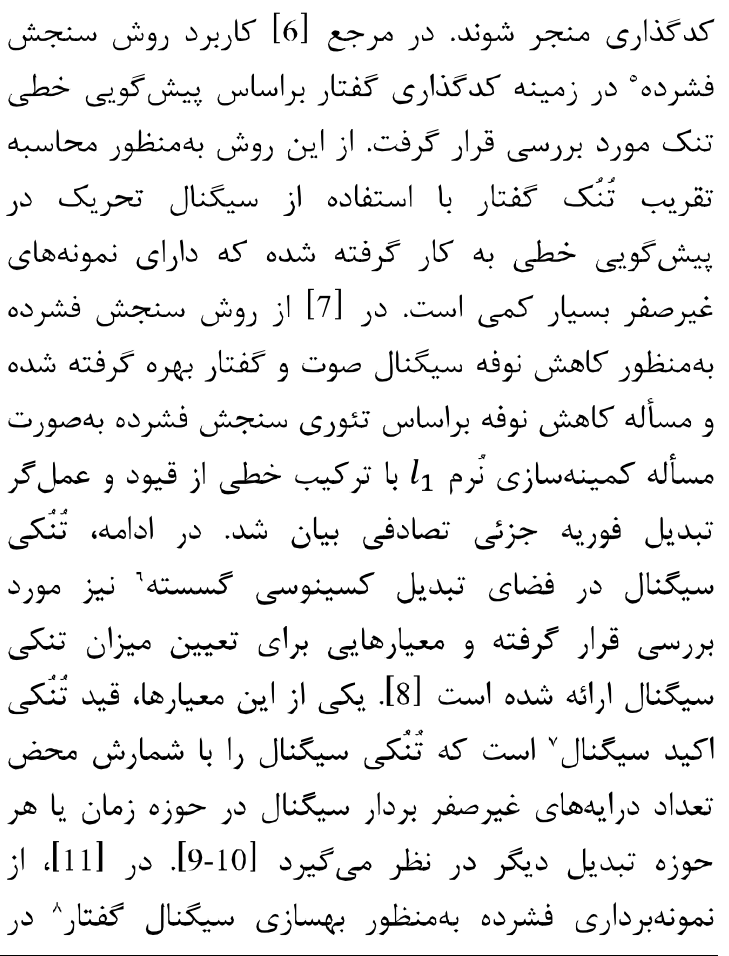

${ }^{5}$ Compressive sensing

${ }^{6}$ Discrete cosine transform

${ }^{7}$ Strict sparsity

${ }^{8}$ Speech enhancement

$$
\begin{aligned}
& \text { - } 1 \\
& \text { بحث نمونهبردارى فشرده' و مفاهيهم مرتبط با آن مانند }
\end{aligned}
$$

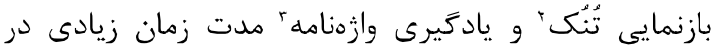

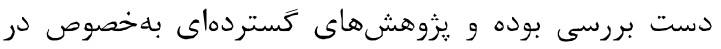

$$
\begin{aligned}
& \text { زمينه يردازش سيخنال تصوير بر روى آن انجام كرفته است. }
\end{aligned}
$$

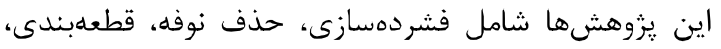

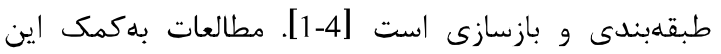

$$
\begin{aligned}
& \text { روشها بهمنظور بهسازى سيخنال كَتتار تنها به سالهاى } \\
& \text { اخير باز مى گردد و يزوهشهاى زيادى در اين زمينه انجام } \\
& \text { نشده است. بحث يردازش كفتار با تكيه بر يادگيرى وازمنامه }
\end{aligned}
$$

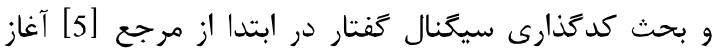

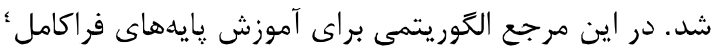

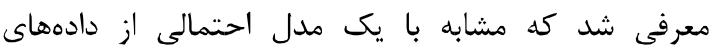

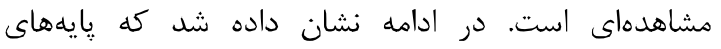

$$
\begin{aligned}
& \text { فراكامل مىتوانند تقريب بهترى از توزيع آمارى دادههاى داى دادي } \\
& \text { مشاهدهاى نمايش داده و به كارايى بيشترى در زمينه }
\end{aligned}
$$

\footnotetext{
${ }^{1}$ Compressive sampling

${ }^{2}$ Sparse representation

${ }^{3}$ Dictionary learning

${ }^{4}$ Overcomplete bases
} 
شد [24]. تُنُكى مضاعف به اين معنى است كه علاوهبر نمايش تُنْك سيكنال، خود وازَّنامه

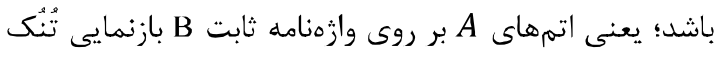

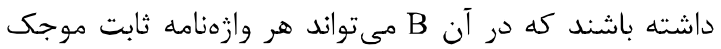

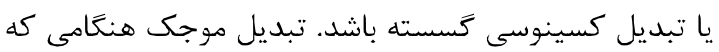

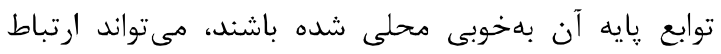

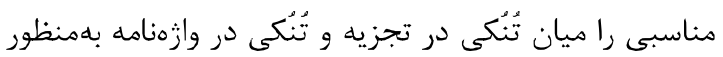

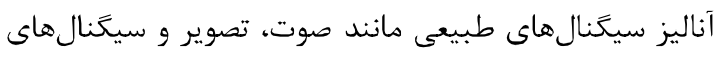

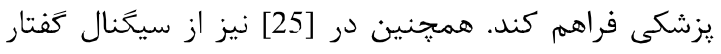

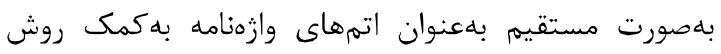

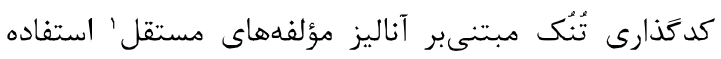

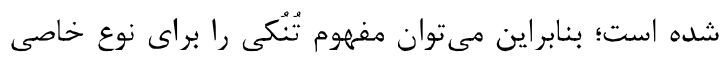

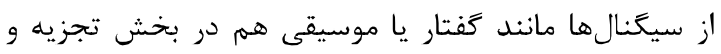

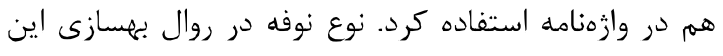

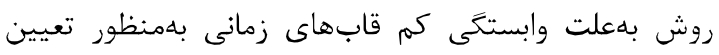

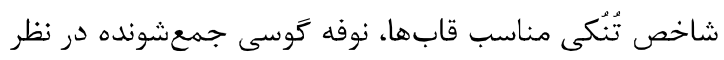

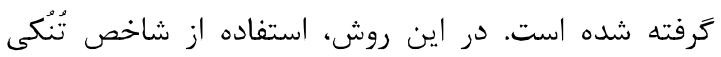

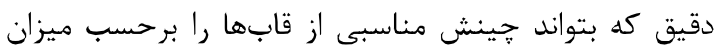

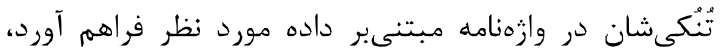

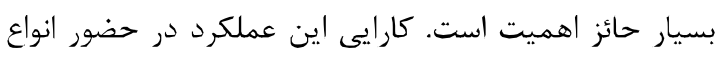

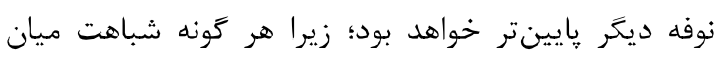

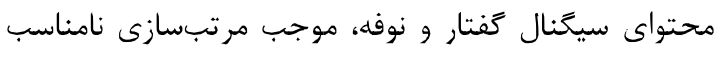

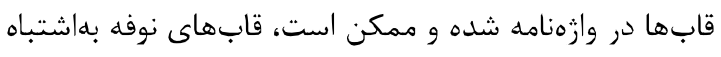

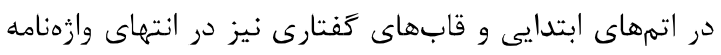

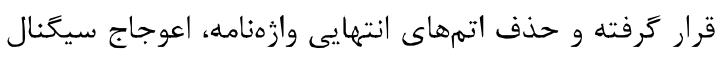

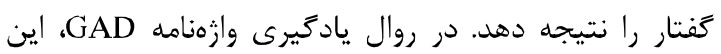

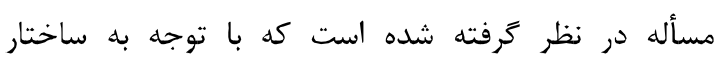

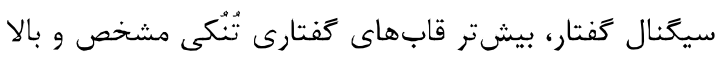

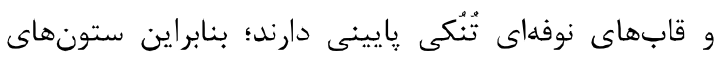

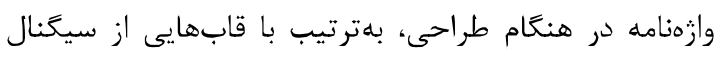

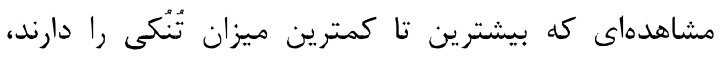

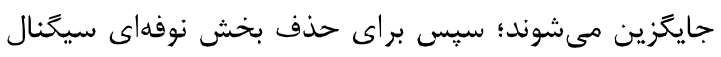
تنها تعداد مشخص و محدودى از ستونهائ اوليه سيكنال

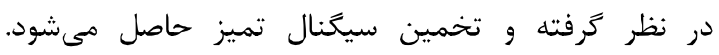

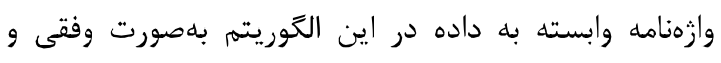

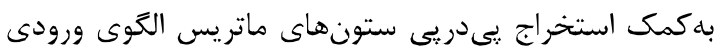

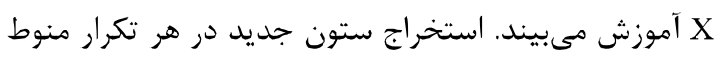

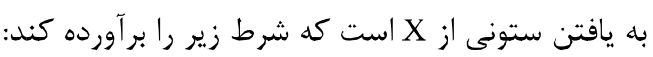
$\xi=\max _{k} \frac{\left\|x_{k}\right\|_{1}}{\left\|x_{k}\right\|_{2}}$

${ }^{1}$ Independent component analysis(ICA)

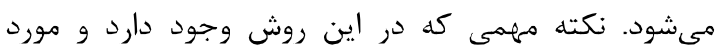

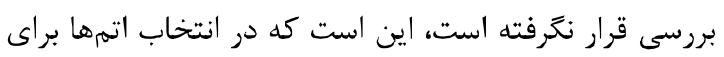

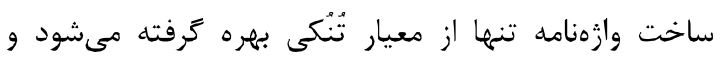

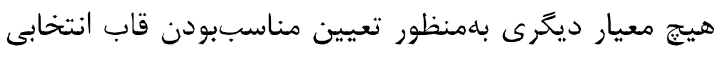

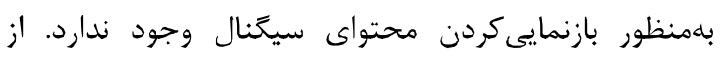

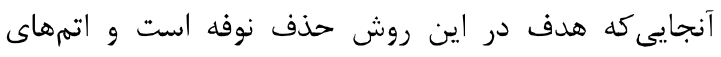

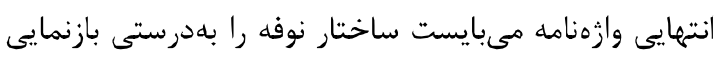

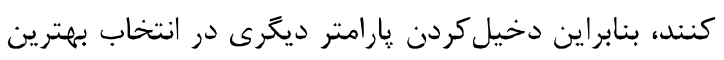

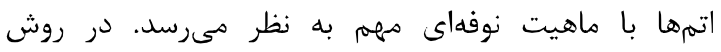

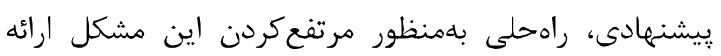

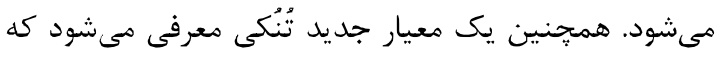

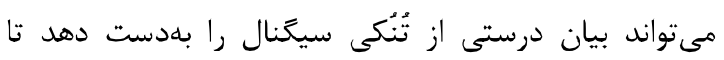
روال حذف نوفه با دقت بالاترى حاصل شودي

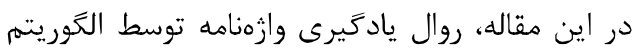

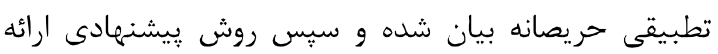

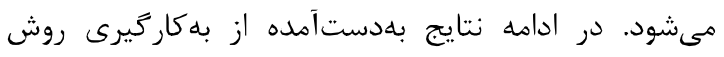
ييشنهادى بهمنظور بهسازى كفتار مورد ارزيابى و مقايسه

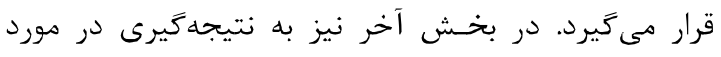
يزوهش انجامشده خواهيم برداخت.

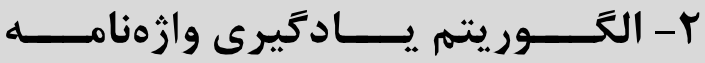 تطبيقى حر يصانه}

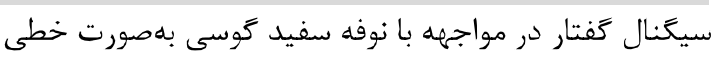

$X(k)=S(k)+N(k)$

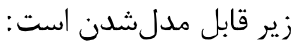

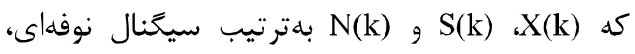
كفتار و نوفه با شماره قاب k هستند. سيكَال نوفهاى مى $\mathbb{R}^{N}$

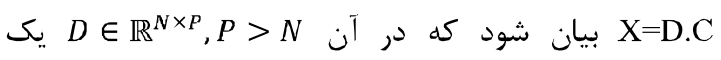

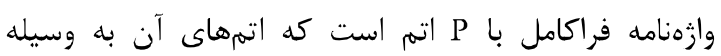
و بردار كدكَارى تُنُك

است نمايش داده مى نشود [5]

$c=\arg \min _{c}\|X-D \cdot c\|^{2}$

, $\|c\|_{0} \leq K_{0}^{c}$

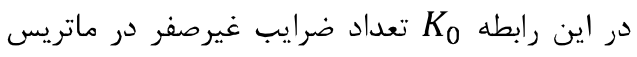

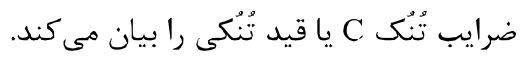

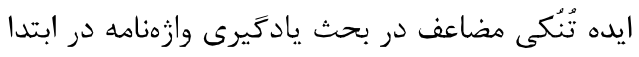

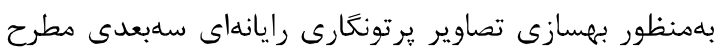


K- مؤلفههاى اساسى' و روش يادگيرى وازمنامه مبتنىبر و همجنين نرخ خطاى بازسازى اين الخوريتهمها در

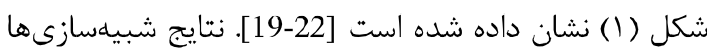
كزارششده در شكلها و جداول اين بخش بر روى يك ده جمله مربوط به يك كوينده زن از مجموعه دادكان

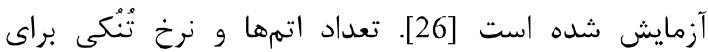
الكوريتم K-SVD بلترتيب برابر با جهارصد و ده تنظيم شده است. همجنين تعداد اتمهاى GAD جهمارصد و تعداد اتمها در PCA، سيصد در نظر كَرفته شده است.

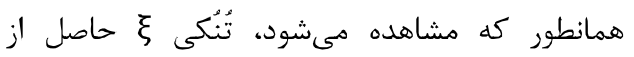
الغوريتم GAD با افزايش تعداد اتمها با شيب ملايمى

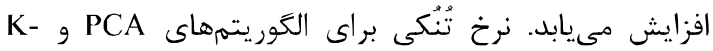
SVD ابتداى كام يادكيرى قابل تنظيم و ثابت است. بنابراين

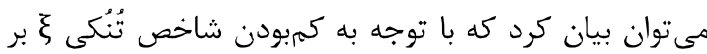

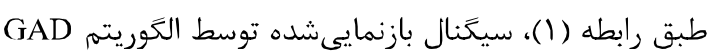

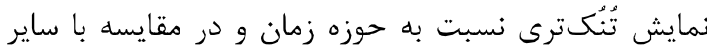

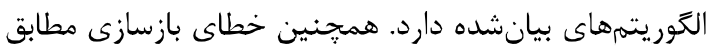
با قسمت (b) براى اين الكوريتم مقدار مناسبى دارد. خطاى دائ تقريب حاصل نيز در جدول (1) بيان شده كه نشان مىدهد

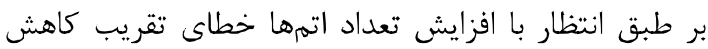
مىيابد. همانطور كه بيان شد در اين روش اتمها بهطور

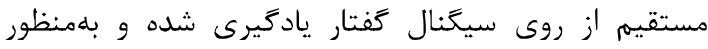

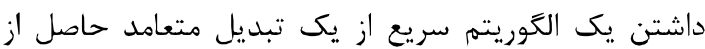
مجموعه قابهاى محلى كه از قاببندى سيخنال كفتار

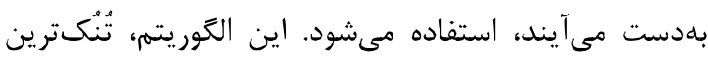

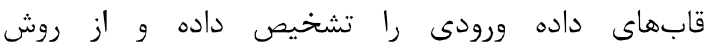

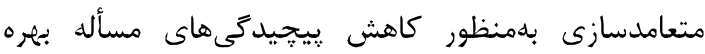
مى گيرد [25].

\section{(جدول -1): خطاى تقريب الكوريتم GAD و PCA.}

(Table-1): The reconstruction error value $\left(\varepsilon \times 10^{-3}\right)$ based on decibel for GAD, PCA and K-SVD algorithms.

تعداد اتمها در وارهنامه

\begin{tabular}{|c|c|c|c|c|c|c|}
\hline & \multicolumn{6}{|c|}{ عداد المها در وازهنامه } \\
\hline & 512 & 400 & 300 & 200 & 100 & 50 \\
\hline GAD & 0.00 & 0.35 & 0.89 & 1.63 & 2.45 & 4.30 \\
\hline PCA & 0.00 & 0.23 & 0.81 & 1.52 & 2.38 & 4.12 \\
\hline K-SVD & 0.00 & 0.21 & 0.97 & 1.71 & 2.65 & 4.67 \\
\hline
\end{tabular}

در كام نهايى الكوريته، دو قانون بهمنظور رسيدن به

تعداد اتمهاى موردنظر يا كاهش خطاى تقريب از مقدار

${ }^{1}$ Principal component analysis(PCA)

${ }^{2} \mathrm{~K}$-Singular value decomposition
بيشينهسازى رابطه بالا برطبق روال زير خواهد بود 1- مقداردهى اوليه: تضمين مىشود كه ستونهاى ماتريس

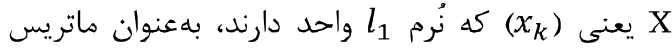
مانده اوليه در نظر گرفته شود:

$\widetilde{x_{k}}=\frac{x_{k}}{\left\|x_{k}\right\|_{1}} \rightarrow R^{0}=\widetilde{X}$

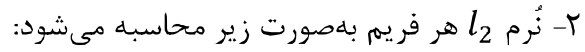

$$
E_{\mathrm{k}}=\left\|r_{k}^{j}\right\|_{2}=\sum_{n=1}^{L}\left|\boldsymbol{r}_{k}^{j}(n)\right|^{2}
$$

در اين رابطه

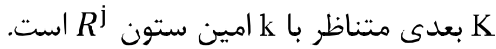
r- شاخص k متناظر با فريمى از سيحنال با بزركترين نُرم ا بهدست مى آيد:

$\hat{k}=\arg \max _{k \in \mathbb{k}}\left(E_{k}\right)$

f- ضريب توسعه با حاصلضرب داخلى بردار مانده و اتم بdدست آمده محاسبه مىشود:

$\alpha_{k}^{j}=\left\langle r_{k}^{j}, d_{j}\right\rangle$

ه- مانده جديد با حذف مؤلفههاى متناظر با اتم انتخابشده براى هر k در ماس محاسبه مي شود:

$r_{k}^{j+1}=r_{k}^{j}-\frac{\alpha_{k}^{j}}{\left\langle d_{j}, d_{j}\right\rangle} d_{j}$

عبارت

كه ضريب توسعه نرماليزهشده خواهد بود. بنابراين ستون

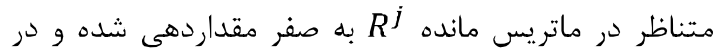
نتيجه موجب متعامدشدن تبديل مىشود. تعامد تبديل

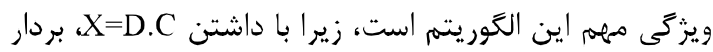

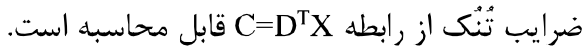
צ- بازگشت به مرحله دوم تا هنگًامى كه تعداد اتمهاى مورد نياز بلهدست آيد [23].

بلهمنظور تعيين ميزان تُنُكى حاصل از يك الكُوريتم

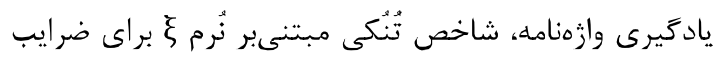
$\xi=\|\mathrm{C}\|_{1} /\|\mathrm{C}\|_{2}$

هر جقرد ميزان اين شاخص تُنْكى كمتر باشد، به

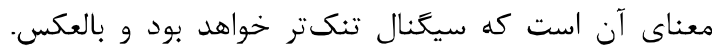

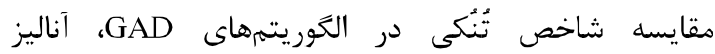


اتمهاى مورد استفاده در وازَهنامه مبتنىبر داده از نظر تُنُكى در يك سطح هستند و ويزگگى بارزى از سيخنال كفتار را بيان نمى كنند.

اتمههاى حاصل از يادگيرى با وازمنامه K-SVD نيز

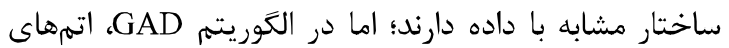
ابتدايى بهدستآمده برخلاف PCA نسبت به اتمهاى انتهايى بهطور كامل خصوصيات محلى سيخنال را به تصوير كشيده و داراى بيشترين تُنْكى هستند.

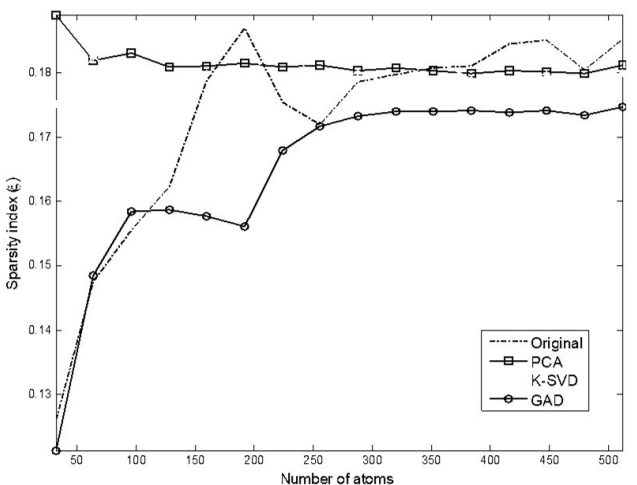

(a)
ييش فرض براى خاتمه الكوريته در نظر گرفته شده است.

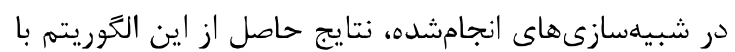
روشهاى يادكيرى وازمنامه ديخر مانند PCA و

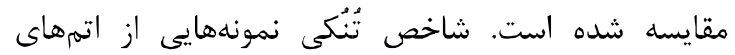
يادكرفتهشده از روشهاى مختلف در شكل (T) نشان داده اسه شده است. همان طوركه ديده مىشود، اتمهاى استخراجشده رونه از روش PCA، خصوصيات دحلى داده را به تصوير نمى كثند؛ يعنى تمامى قابهاى برززيدهده بلهنوان

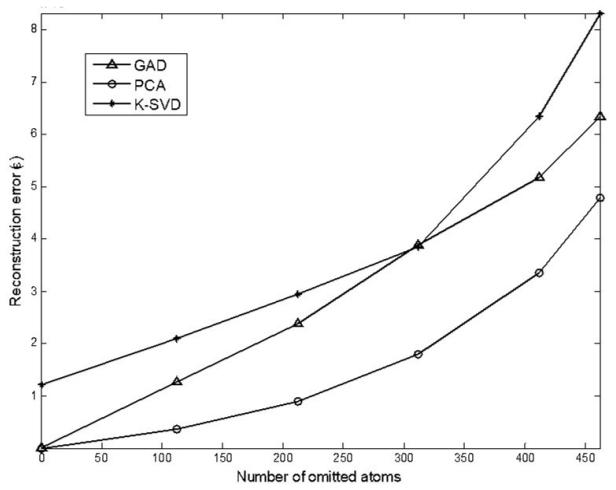

(b)

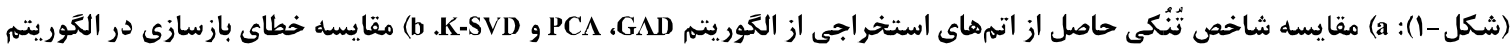
.K-SVD و PCA ،GAD

(Figure-1): a) Comparison of sparsity index of speech frames extracted from GAD, PCA and K-SVD algorithms. b) Comparison of reconstruction error for GAD, PCA and K-SVD algorithms.

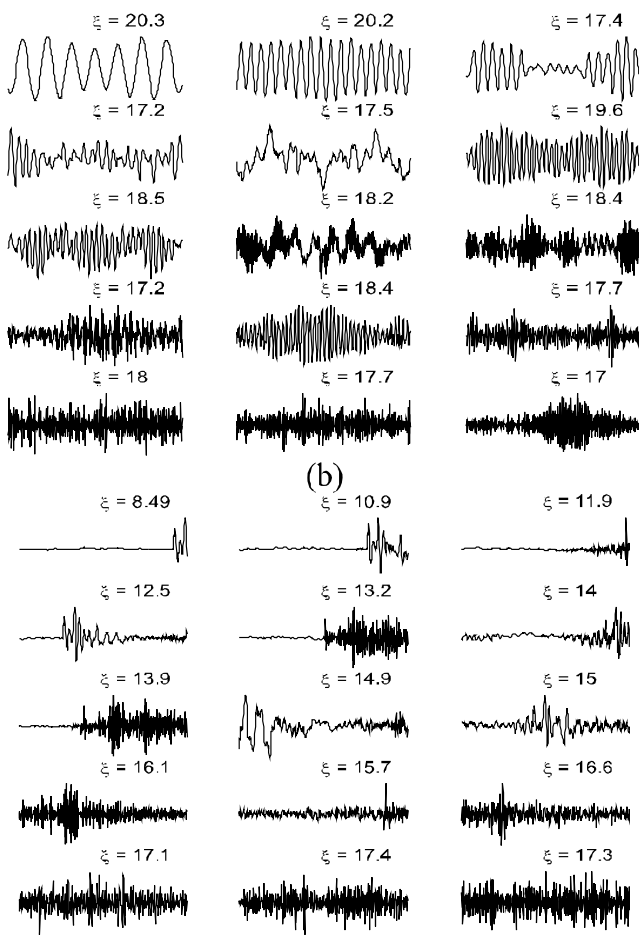

(d)

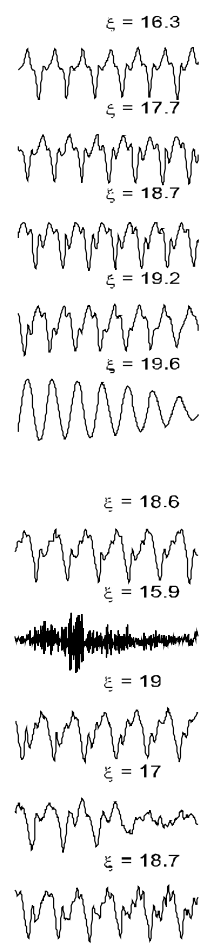

Nap $N$

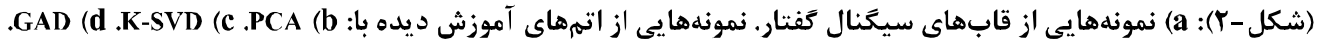

(Figure-2): a) The selected frames of speech signal. The examples of the learned atoms using: b) PCA. c) K-SVD. d) GAD algorithms. 
توسط دالتون در [30] مطرح شده است. نكته قابل توجه آن

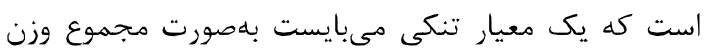

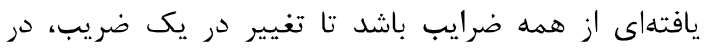

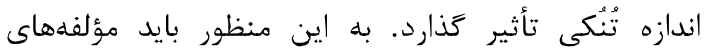
كوجى نسبت به مؤلفههاى بزر

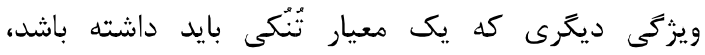
نرماليزهبودن آن است. بدين معنا كه يك مجموعه از ضرايب

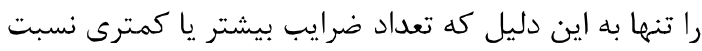

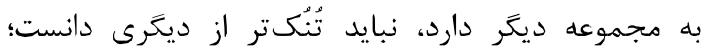

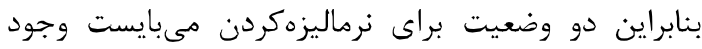

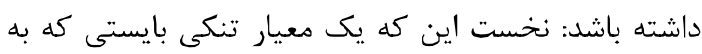
مقدار نسبى ضرايب بلصورت تابعى از مقدار كلى وابسته

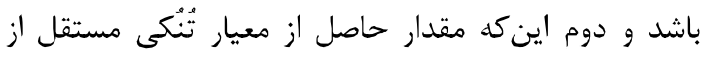

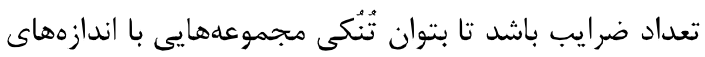

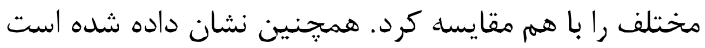

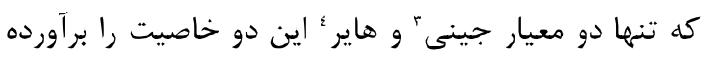

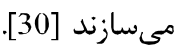

همجنين تنها معيارى كه تمام ويركى هاى شش كانه

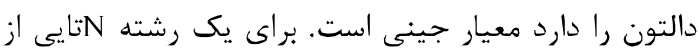
ضرايب بيان مىشوند [30].

$$
\begin{aligned}
& C=\left(\sqrt{N}-\frac{\sum_{j} c_{j}}{\sqrt{\sum_{j} c_{j}^{2}}}\right)(\sqrt{N}-1)^{-1} \\
& \text { Gini }=1-2 \sum_{j=1}^{N} \frac{c_{j}}{\|\vec{C}\|_{1}}\left(\frac{N-j+\frac{1}{2}}{N}\right)
\end{aligned}
$$

با استفاده از نتايج كزارششده در [28-28]، استفاده

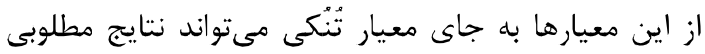

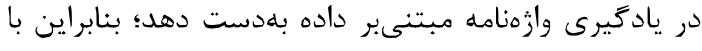

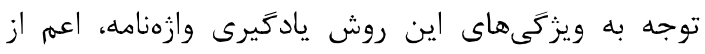

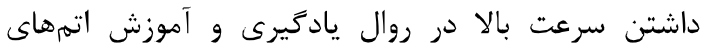

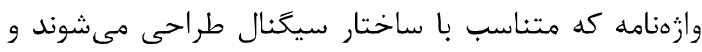

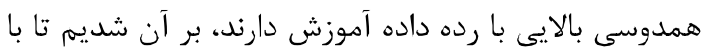

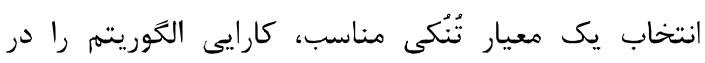
حذف نوفه بهبود دهيم.

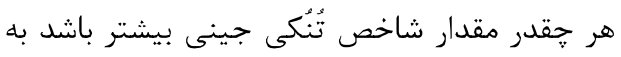

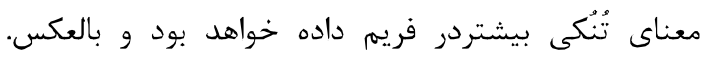

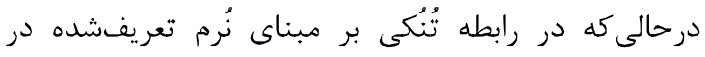

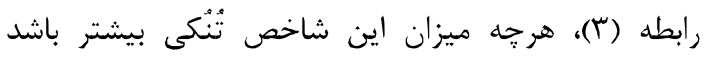

\footnotetext{
${ }^{3}$ Gini
}

${ }^{4}$ Hoyer
مطابق شكل (r)، اتمهاى يادكيرىشده از قابهاى

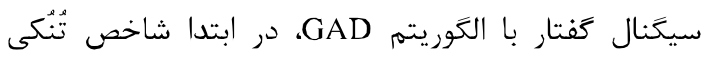

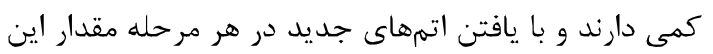

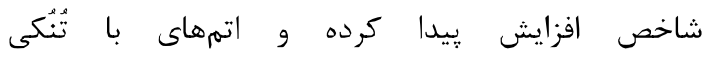

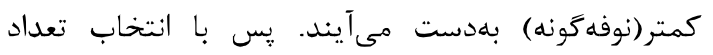

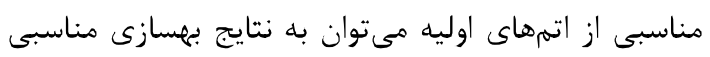

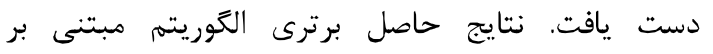

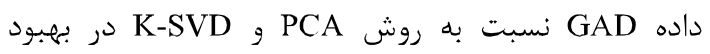

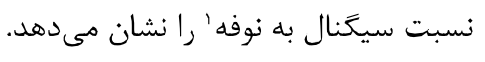

\section{" - روش بيشنهانى}

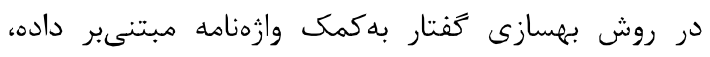
حذف اتمهاى وازمهنامه بدون توجه بهار به اين مسأله صورت

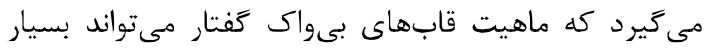

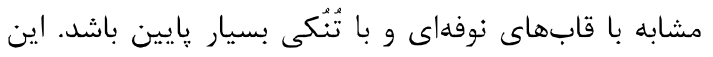

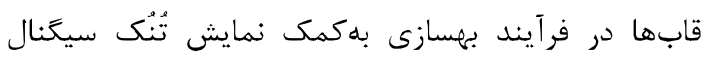

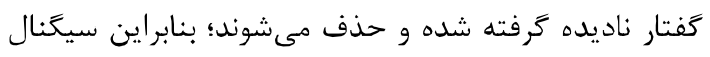

$$
\text { كفتار تخمينى با اعوجاج منبع حاصل مى شود. }
$$

در اين صورت مىبايست از قابهاى ابتدايى كه مداصن

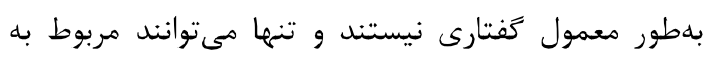

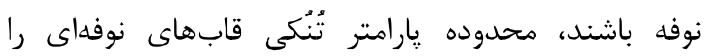

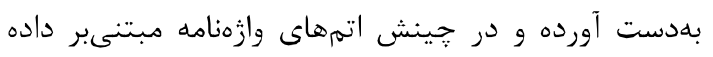

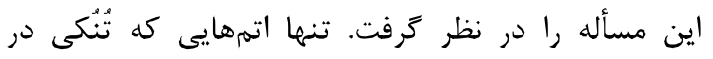

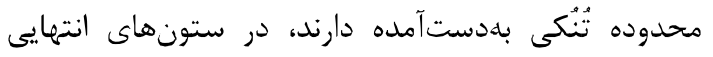

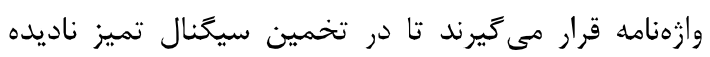

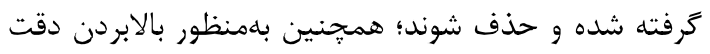

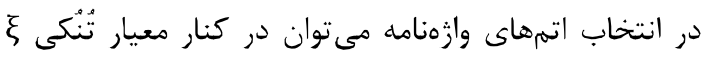

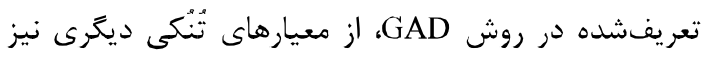
بهره برد.

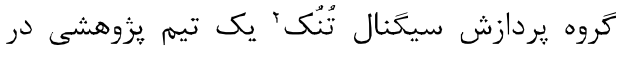

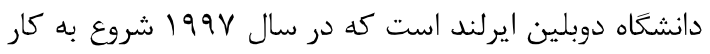

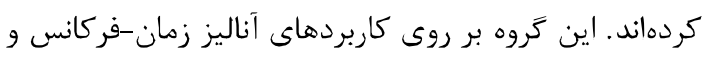

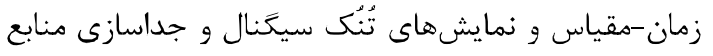

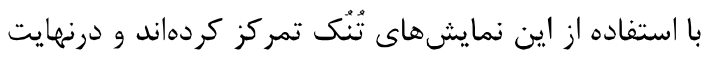

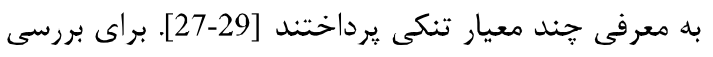

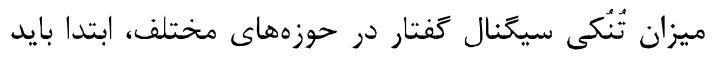

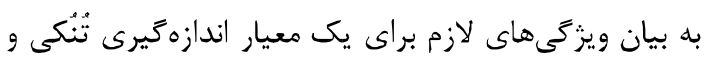

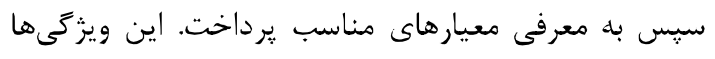

${ }^{1}$ Signal to noise ratio(SNR)

${ }^{2}$ Sparse signal processing team 
تُنُكى قابهايى اوليه سيخنال مشاهدهاى كه ماهيت نوفهاى دارند در انتخاب ستونهاى وازثنامه مبتنى داده بسيار مؤثر خواهد بود. همانطوركه ديده مىشود، قابهاى استخراجشده براساس بيشينه ميزان تُنُكى

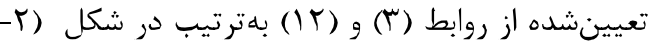
d و شكل (r) بسيار مشابه هستند؛ اما در قابهاى

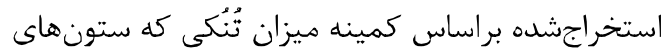
ابتدايى در وازمنامه مبتنىبر داده را تعيين مى كند، اندكى تفاوت دارند.

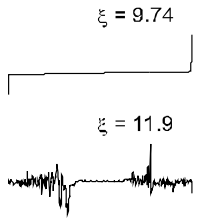

$\xi=16.6$

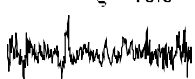

$\xi=17.8$

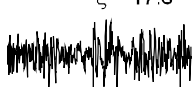

$\xi=17.2$

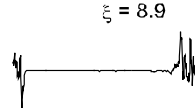

$\xi=15.9$

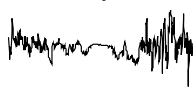

$\xi=16.8$

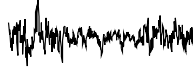

$\xi=16.7$

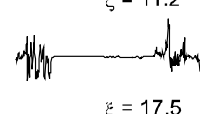

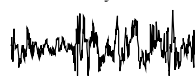

$\xi=16.9$

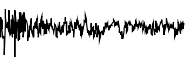

$\xi=17$

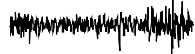

$\xi=18$

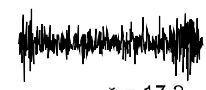

$\xi=17.2$

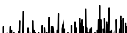

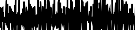

(شكل-r): نمونه هايى از اتمهاى آموزش ديده با الكَوريتم

.GAD_Gini

(Figure-3): The examples of the learned atoms using GAD_Gini algorithms.

درواقع قاب حاصل از رابطه يِيشنهادى كه بر مبناى

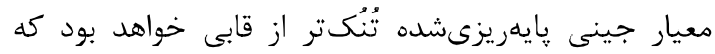

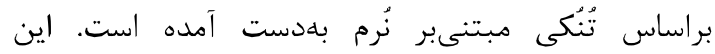

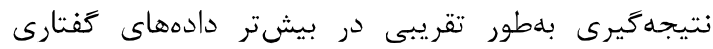
متعلق به گويند در مورد نحوه انتخاب اتمهاى ابتدايى ماتريس وازمنامه نيز همانطوركه بيان شد از اطلاعات حاصل از

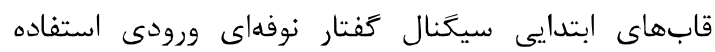
مىشود. بد اين معنى كه تنها قابهايى از داده در ابتداى

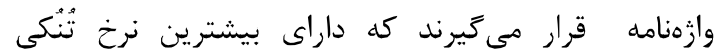
براساس رابطه (T) (I) باشند و اين مقدار تُنُكى حاصل، خارج

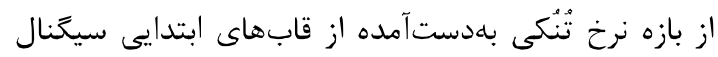

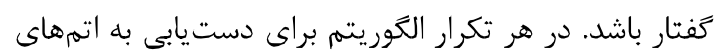

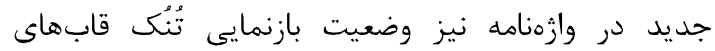

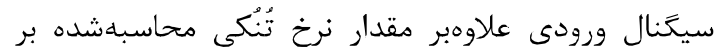
روى وازّهامه بررسى مى شود و قابهايى در ابتداى وازّهنامه

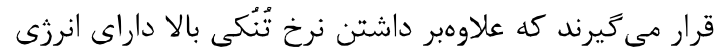

بلمعناى سيكنال با تُنُكى كمتر خواهد بود. شاخص تُنُكى ييشنهادشده در اين بخش براساس معيار جينى و بلهصورت

$\xi_{\text {Gini }}=\max \frac{\left\|x_{k}\right\|_{1}}{\operatorname{Gini}\left(\left|x_{k}\right|\right)}$

زير تعريف مىشود:

k در اين رابطه، شماره قاب سيخنال ورودى است. با

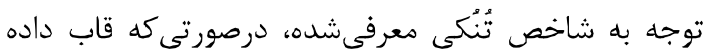

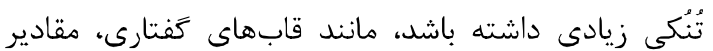

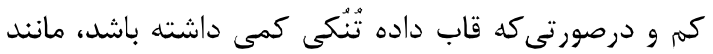

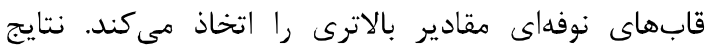

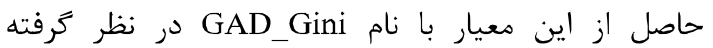
مىشود؛ همجنين مورد ديخر در روش پيشنهادى اين است

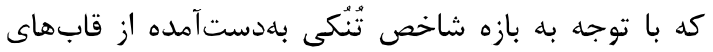

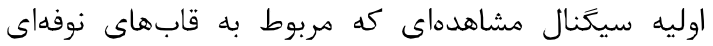

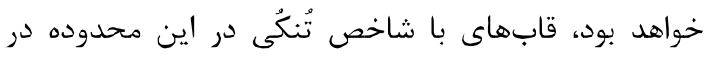

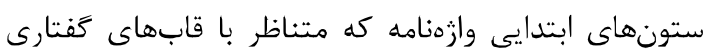
است قرار نمى

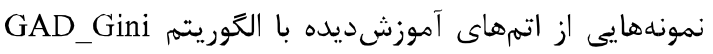

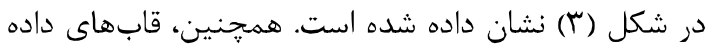

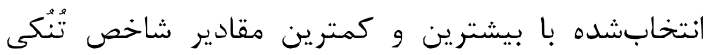

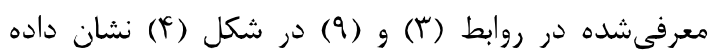
شده است. قابل ذكر است كه نتايج حاصل از معيار هاير بهعلت

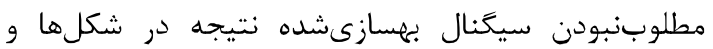

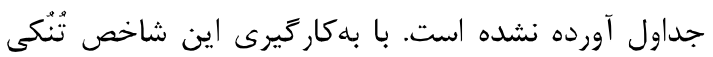

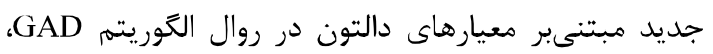

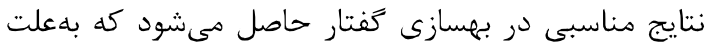

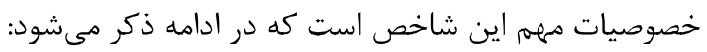
(1) شاخص جينى بلصورت مجموع وزن يافتهاى از همه ضرايب موجود محاسبه مىشود تا تغيير در يك ضريب حتى كوجى در اندازه تنكى كل تأثير بحذارد. بنابراين

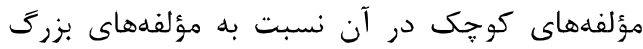
داراى وزن بيشترى هستند.

r) اين شاخص نسبت به تعداد ضرايب نرماليزه شده است وانت تا يك مجموعه از ضرايب را تنها به اين دليل كه تعداد ضرايب بيشتر يا كمترى نسبت به مجموعه ديخر دارد يا

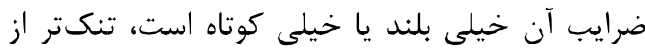
ديخرى تعيين نكنند. r) مقدار اين شاخص براى بخشئهاى نوفهاى متمايز از بخشهاى گَفتارى است؛ بنابراين درنظرگرفتن شاخص 


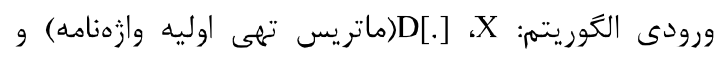

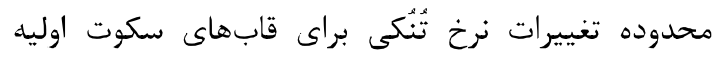

سيكنال كفتار (ع)

خروجى الكوريته: D م Sparsity measure based on Gini coefficients

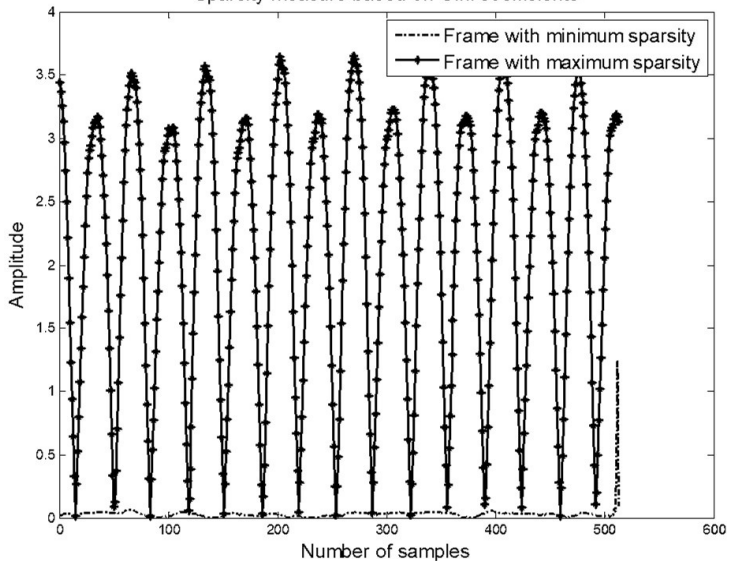

(b)

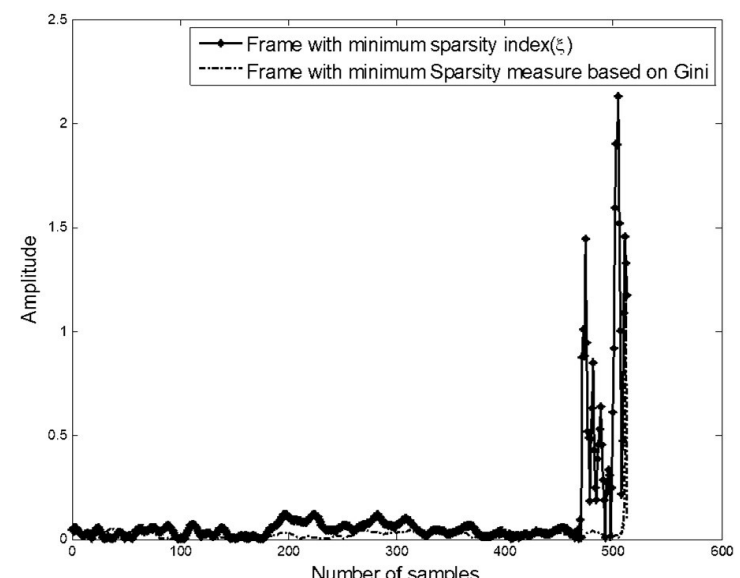

(d)

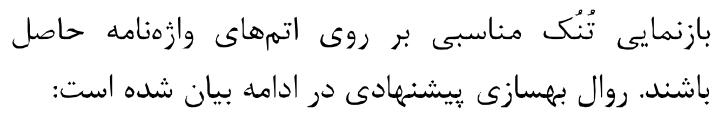

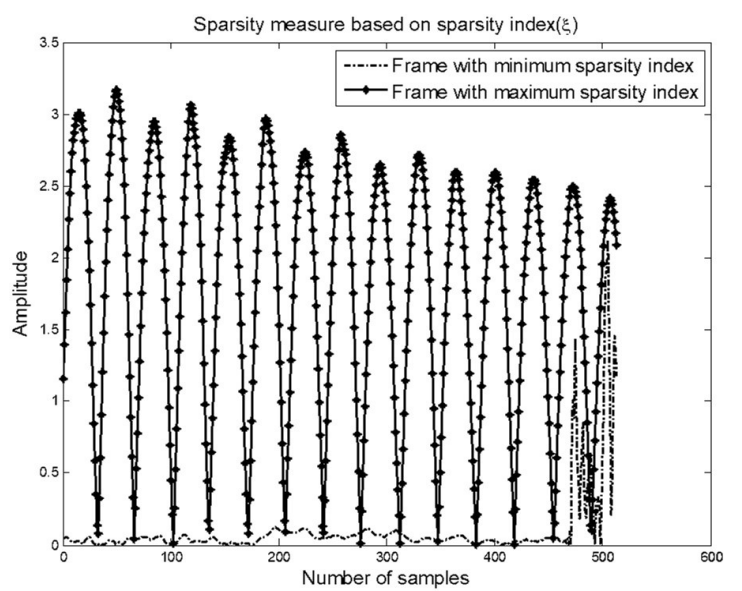

(a)

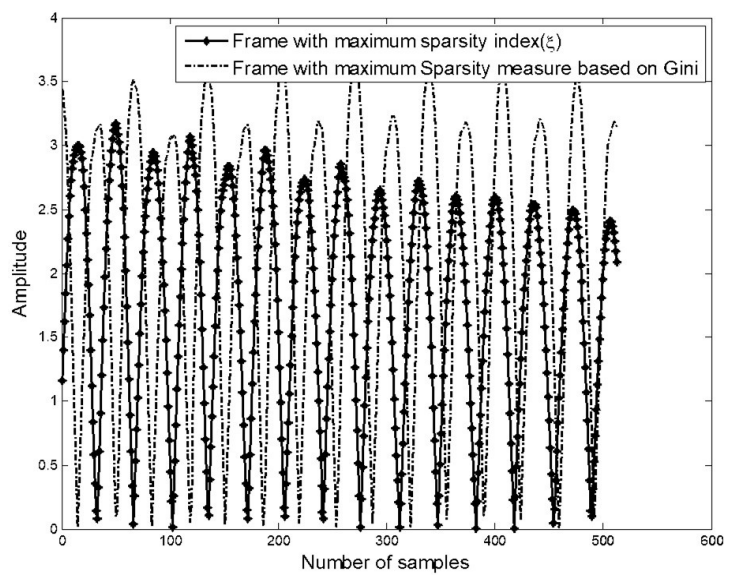

(c)

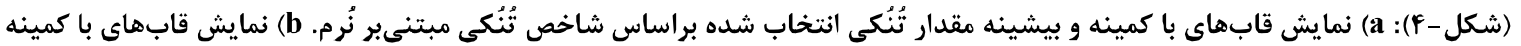

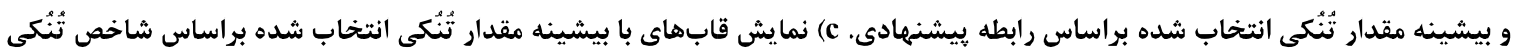

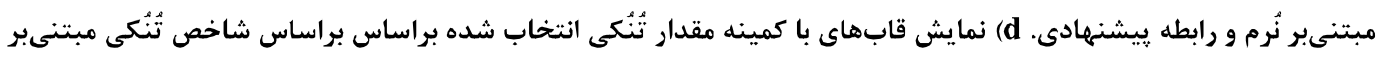
نُرم و رابطه بيشنهادى.

(Figure-4): a) The representation of speech frames with minimum and maximum sparsity values selected based on the norm-based sparsity index. b) The representation of speech frames with minimum and maximum sparsity values selected based on the proposed sparsity index. $c$ ) The representation of speech frame with maximum sparsity values selected based on the norm-based sparsity index and the proposed sparsity index. d) The representation of speech frame with minimum sparsity values selected based on the normbased sparsity index and the proposed sparsity index.

$$
\begin{aligned}
& \text { ( ) محاسبه G-t }
\end{aligned}
$$

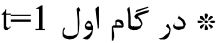

$$
\begin{aligned}
& \text { نوفهاى }
\end{aligned}
$$

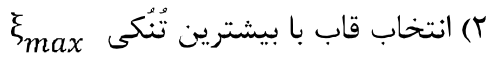

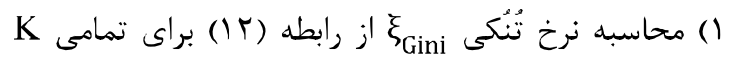

$$
\begin{aligned}
& \text { قاب سيكنال تفتنار نوفهاى } \\
& \text { r) اتر } \\
& \text { ك) انتخاب قاب با بيشترين تُنْكى }
\end{aligned}
$$

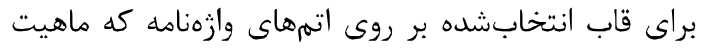

$$
\begin{aligned}
& \text { Fفتارى دارند، بهاندازء كافى زياد باشد، يعنى: } \\
& \|C\|_{2}>0.4\|X\|_{2} \leftarrow\left(X_{k}\right)_{\xi_{\max }}=D_{t} . C \\
& \text { Dن }
\end{aligned}
$$

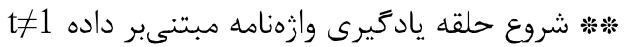


بلهمنظور بررسى شاخص تُنُكى، ميانكَين مقدار اين

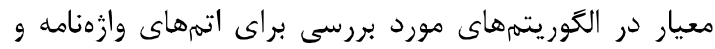

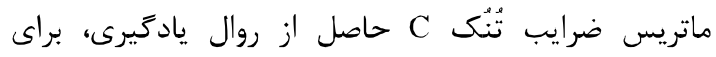

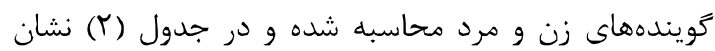

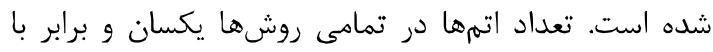

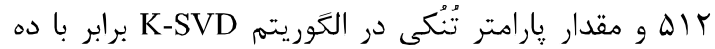
در نظر گرفته شده است. در اين نتايج، نتايج حاصل از ازئ

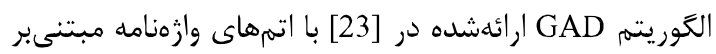

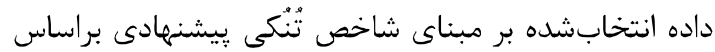

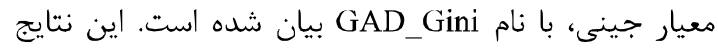
حاصل ميانكينگيرى بر روى رئن صد سيخنال كفتارى

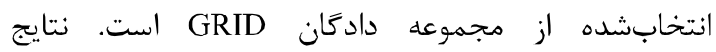

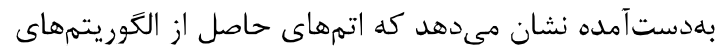
مبتنى GAD

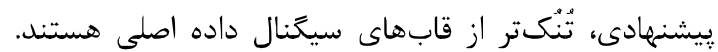

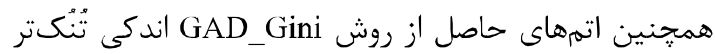

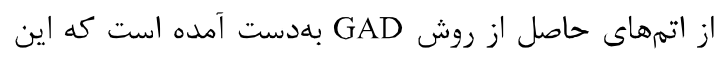

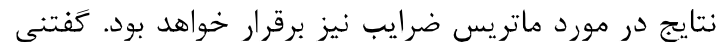

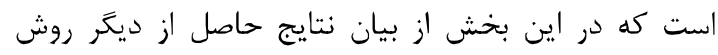

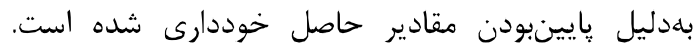

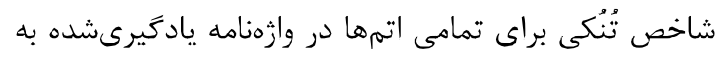

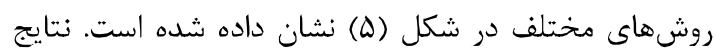
در اين شكل در SNR=0 حاصل شده است. همانطوركه از

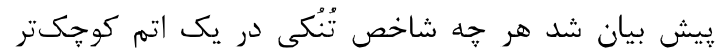

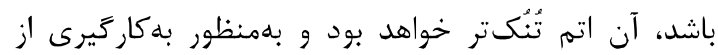

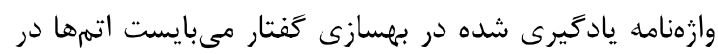

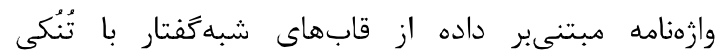

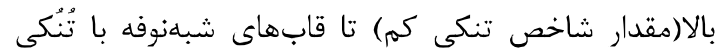

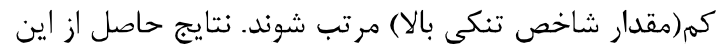

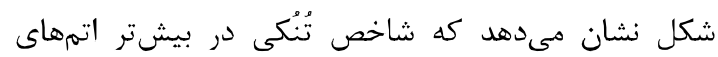

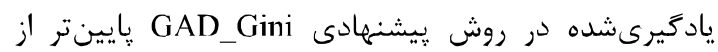
ساير روشها و داده اصلى بهدست آمده است كه ند نشان مىدهد تُنُكى اتمهاى حاصل بيشتر از داده كَفتارى خواهد بود. همجنين مىتوان مشاهده كرد كه در الكَوريتم GAD و GAD_Gini

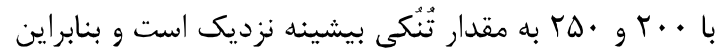

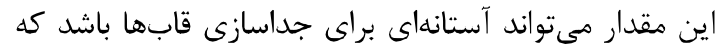

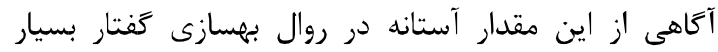

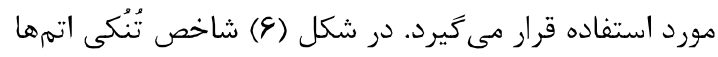

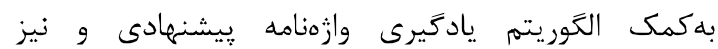
بهكارگيرى بخشهاى آن شامل اعمال محدوده بر شاخد
قاب انتخابشده به ستون بعدى ماتريس وارثنامه اختصاص

مى $\mathrm{D}_{t} \leftarrow\left(X_{k}\right)_{\xi_{\max }}$

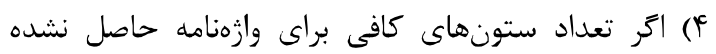

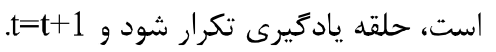

به اين صورت در هر كام يك اتم به ماتريس وازمنامه

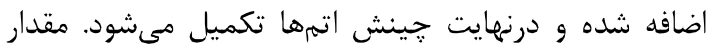

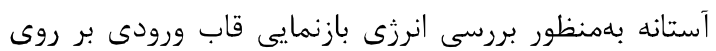

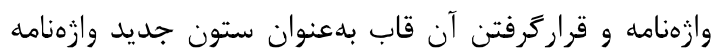

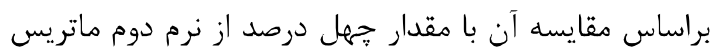
قابهاى ورودى X در كام سوم خواهد بود كه اين ميزان

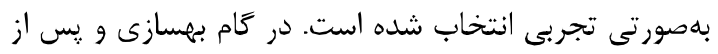

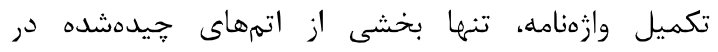

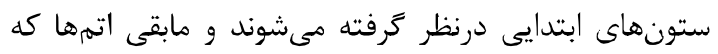

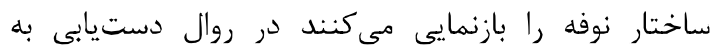

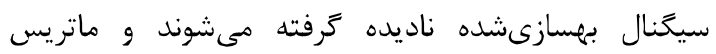
وازمنامه ستونها بهمنظور بازسازى سيخنال كفتار مورد استفاده قرار

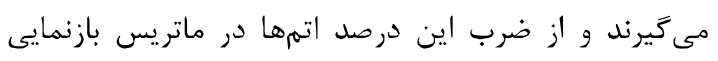

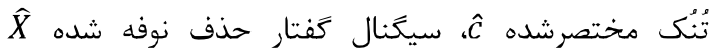

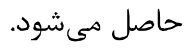

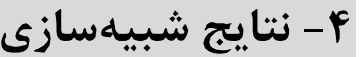

داده كفتارى مورد نياز از مجموعه دادكان GRID براى سياى

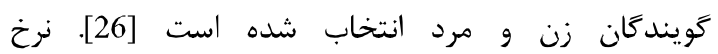

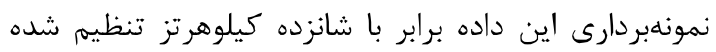

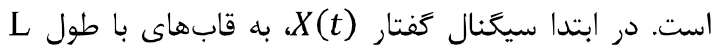

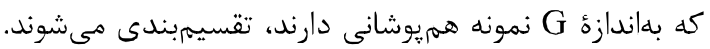
Kأمين قاب بلصورت زير بهدست مى آيد:

$X_{k}=[X((k-1)(L-G)+1), \ldots, X(k l-(k-1) G)]^{T}$

كه در آن $k \in\{1, \ldots, K$ شماره قاب مورد بررسى است. سيس از قابهاى ساختهشده ماتريس

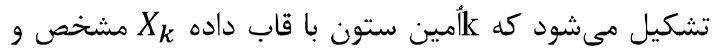
(1,k)

$[X]_{l, k}=X(l+(k-1)(L-G))$

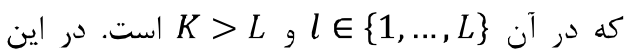

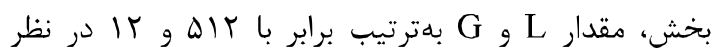
كرفته شده كه بيان

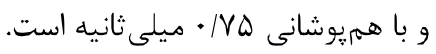


بdازاى SNR=0 نمايش داده شده است. همانطوركه ديده

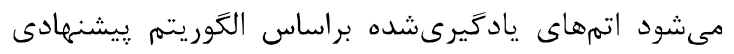
GAD_Gini

$$
\text { مشخصات آن را بازنمايى كند. }
$$

(جدول-r): ميانغَين شاخص تُنُكى در الكَور يتمهاى مختلف براى

اتمها و ماتريس ضرائ

(Table-2): The average values of atom sparsity index and sparsity for coefficient matrix of different algorithms

\begin{tabular}{|c|c|c|c|c|}
\cline { 2 - 5 } Method & \multicolumn{2}{c|}{$\begin{array}{c}\text { Atom sparsity } \\
\text { index }\end{array}$} & \multicolumn{2}{c|}{$\begin{array}{c}\text { Sparsity of } \\
\text { coefficient matrix }\end{array}$} \\
\cline { 2 - 5 } & Female & Male & Female & Male \\
\hline Speech data & 0.1741 & 0.1673 & 0.1741 & 0.1673 \\
\hline PCA & 0.1722 & 0.1731 & 0.1527 & 0.1597 \\
\hline K-SVD & 0.1643 & 0.1724 & 0.1336 & 0.1387 \\
\hline GAD & 0.1531 & 0.1641 & 0.1371 & 0.1357 \\
\hline GAD_Gini & $\mathbf{0 . 1 4 7 6}$ & $\mathbf{0 . 1 4 3 1}$ & $\mathbf{0 . 1 1 0 7}$ & $\mathbf{0 . 1 2 0 2}$ \\
\hline
\end{tabular}

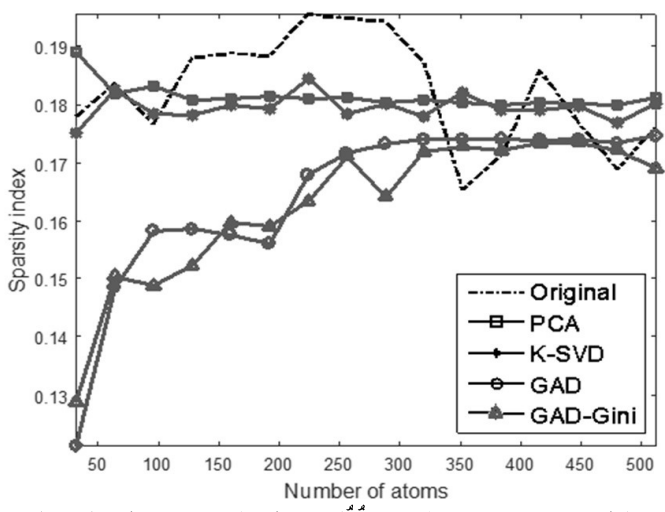

(شكل -ه)): بررسى شاخص تُنْكى براى اتمها در وازٔهنامههاى

يادكيرىشده با روش اشهاى مختلف لئل

(Figure-5): Plot of sparsity index of atoms in the learned dictionaries of different algorithms

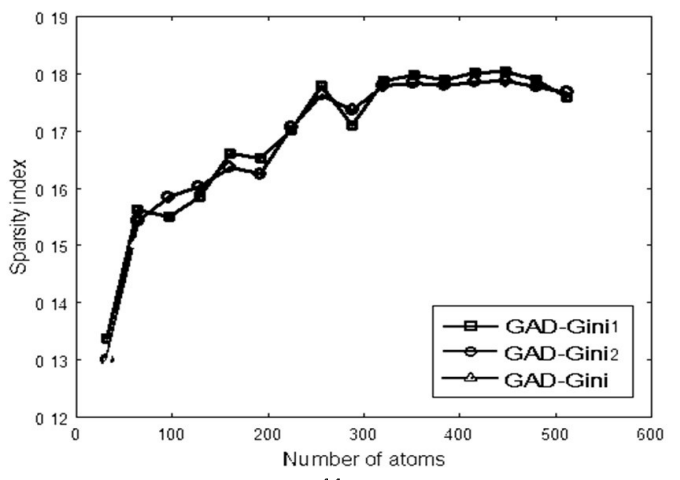

(شكل - ()): بررسى شاخص تُنُكى اتمها در وازمنامههاى

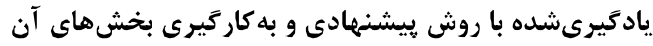

(Figure-6): Plot of sparsity index of atoms based on the proposed dictionary learning algorithm and its different steps
تُنُكى بهكمى قابهاى ابتدايى و نيز بهكارگيرى شاخص

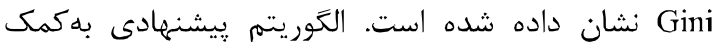

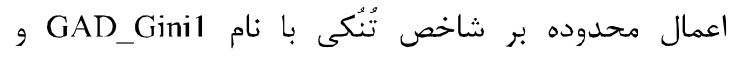

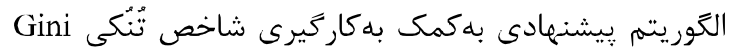

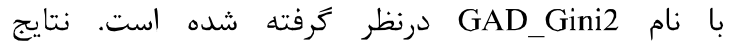

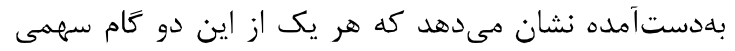

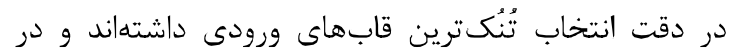
كنار يكديخر توانستهاند، نتيجه مطلوبى در اين راستا بهدست

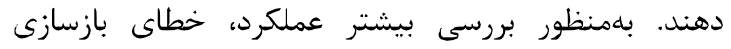

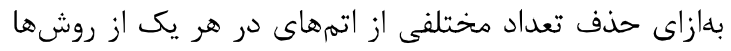
محاسبه شده و در شكل (V) نمايش داده شده است. نتايج اين شكل در SNR=0 بهدست آمده است. محدوده اين تعداد

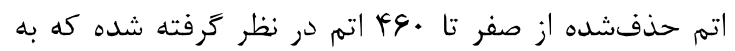

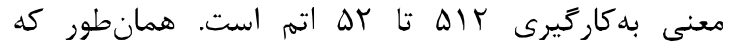

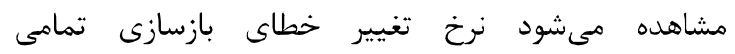

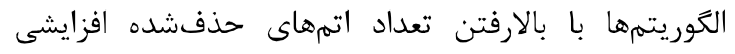

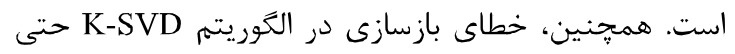

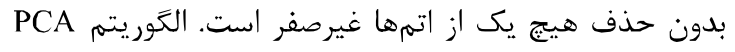

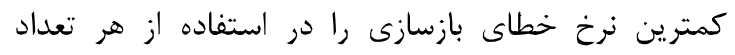

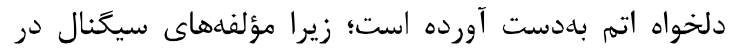

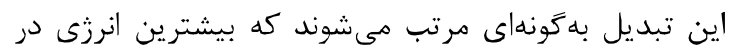
تعداد بسيار كمى از مؤلفهها متمركز شود و اين مؤلفهها همان اتمهايى هستند كه زودتر استخراج مىشوند. همجنين مونين

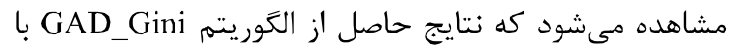
تعداد اتمهاى حذفشده كمتر مناسبتر از الخوريتم بر مبناى است و از آنجايى كه مواردى با تعداد اتمهاى حذفشده زياد بهطور معمول رخ نمى دهد، ابتداى اين نمودار

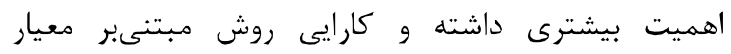
مناسبتر خواهد بود. نتايج حاصل از خطاى

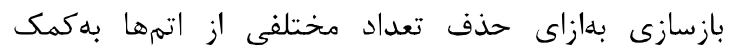

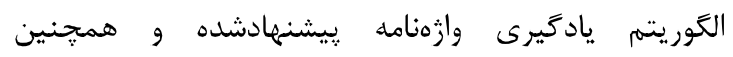

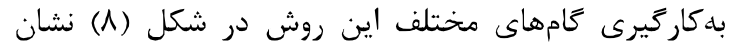

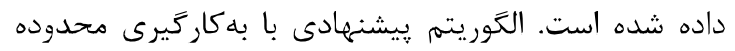

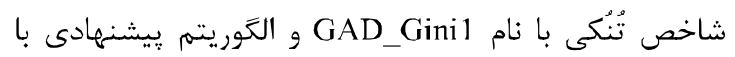

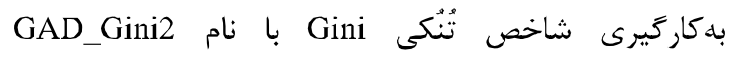
نامَذارى شده است. نتايج نشان مىدهد كه اعمال هر يك از

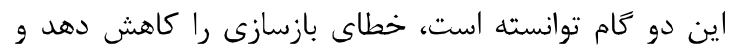

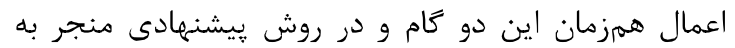
كاهش خطاى بازسازى محسوسى شده است.

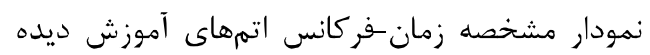

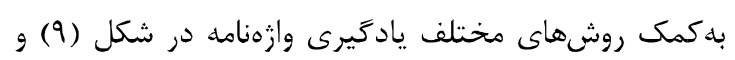




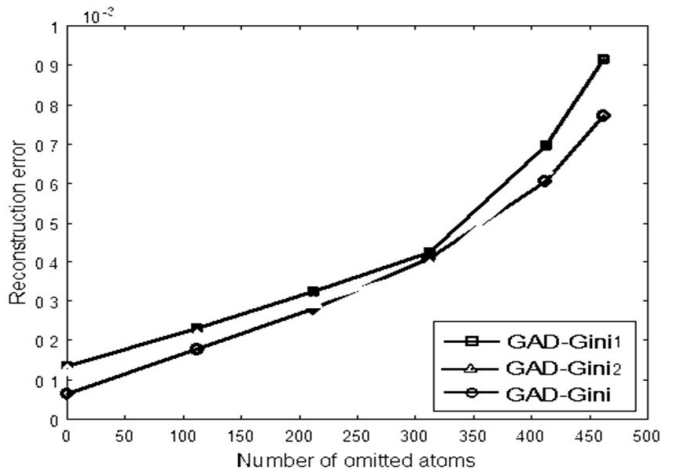

(شكل-1): مقايسه خطاى بازسازى بهازاى حذف تعداد مختلفى

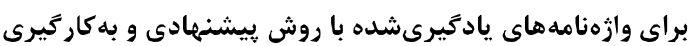

$$
\text { بخش هاى آن }
$$

(Figure-8): Comparison of the reconstruction error of sparse representation by removing different number of atoms based on the proposed dictionary learning algorithm and its different steps
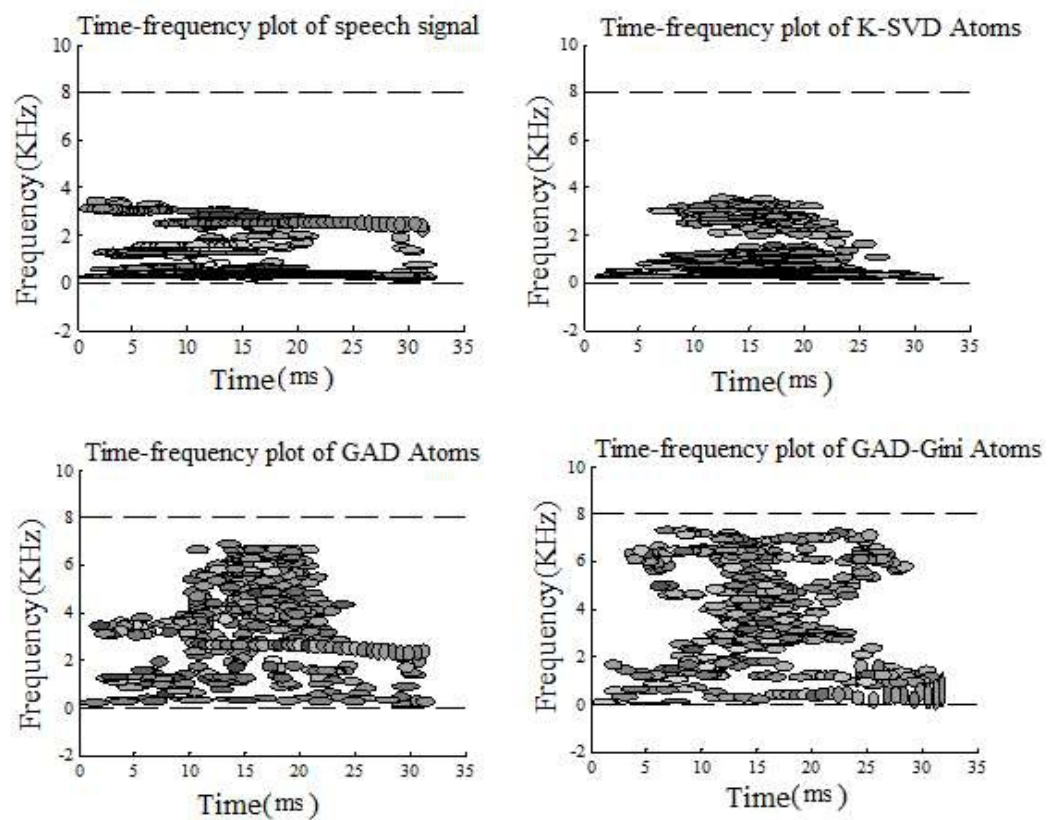

(شكل-9): نمايش بازنمايى مشخصات زمان-فركانس توسط اتمهاى وازٔنامه آموزش ديده بهكمى الكوريتمهاى مختلف

(Figure-9): Plot of time-frequency structure of the atoms learned using different methods

$I S N R=10 \log \frac{E\left\{(x(t)-y(t))^{2}\right\}}{E\left\{(x(t)-\hat{x}(t))^{2}\right\}}$

كه در آن

داده اصلى، سيخنال نوفهاى مشاهده شده و سيخنال بهسازىشده هستند. همانطور كه قابل نتيجه گيرى است، هر خه سيخنال بهسازىشده به سيخنال اصلى شبيهتر باشد،

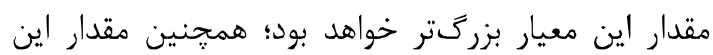
دعيار در تمامى روشهاى مورد بررسى به جز K-SVD، هنگًامى كه از تمامى اتمها در روال بازسازى استفاده شود، مقدار صفر خواهد داشت و بازسازى كامل خواهد بود؛ اما در

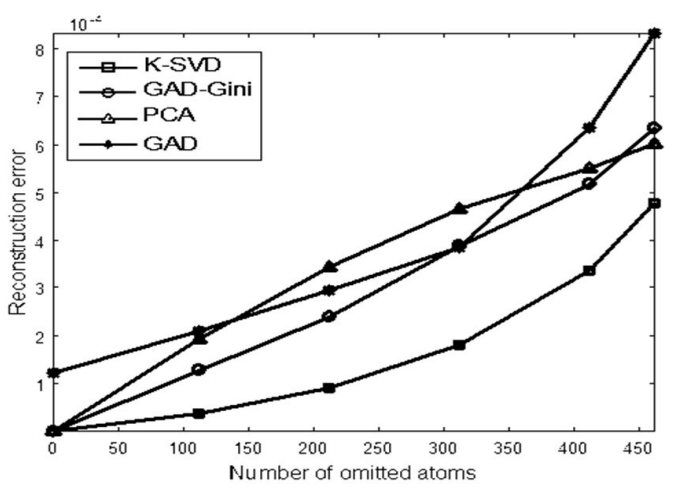

(شكل-V-): مقايسه خطاى بازسازى بهازاى حذف تعداد مختلفى از

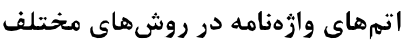

(Figure-7): Comparison of the reconstruction error of sparse representation by removing different number of atoms

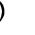


ميزان اتمهاى حذف شده بيشتر باشد، نتايج بهسازى بهترى

بهدست خواهد آمد.
ساير شرايط كه تعدادى از اتمها در نظركرفته نمىشوند،

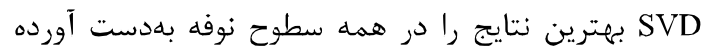

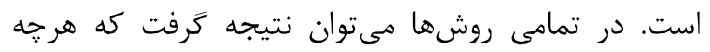

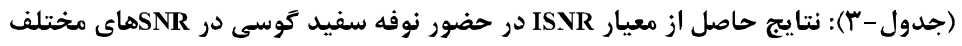

(Table-3): The results of ISNR value in the presence of white Gaussian noise in different SNR values

\begin{tabular}{|c|c|c|c|c|c|c|c|}
\hline \multirow{2}{*}{ SNR } & \multirow{2}{*}{ Method } & \multicolumn{6}{|c|}{ Number of atoms in dictionary } \\
\hline & & 512 & 400 & 300 & 200 & 100 & 50 \\
\hline \multirow{5}{*}{$-10 \mathrm{~dB}$} & PCA & 0 & 0.48 & 1.44 & 2.37 & 4.69 & 5.73 \\
\hline & K-SVD & 5.41 & 6.08 & 6.52 & 6.41 & 5.29 & 4.11 \\
\hline & $\mathrm{GAD}$ & 0 & 1.27 & 2.94 & 4.33 & 4.98 & 4.07 \\
\hline & GAD Gini & 0 & 2.29 & 3.97 & 4.87 & 5.01 & 4.26 \\
\hline & OMLSA & \multicolumn{6}{|c|}{4.71} \\
\hline \multirow{5}{*}{$0 \mathrm{~dB}$} & PCA & 0 & 0.46 & 1.31 & 2.71 & 5.41 & 8.20 \\
\hline & K-SVD & 5.69 & 6.91 & 7.18 & 7.57 & 8.53 & 10.05 \\
\hline & GAD & 0 & 1.31 & 2.69 & 5.22 & 7.24 & 9.14 \\
\hline & GAD Gini & 0 & 2.43 & 3.56 & 6.42 & 8.07 & 7.18 \\
\hline & OMLSA & \multicolumn{6}{|c|}{7.24} \\
\hline \multirow{5}{*}{$-10 \mathrm{~dB}$} & PCA & 0 & 0.51 & 1.31 & 2.72 & 5.48 & 8.29 \\
\hline & K-SVD & 5.82 & 6.75 & 7.56 & 9.91 & 12.51 & 13.68 \\
\hline & GAD & 0 & 1.31 & 2.84 & 5.31 & 7.69 & 9.28 \\
\hline & GAD Gini & 0 & 1.54 & 3.12 & 6.57 & 8.24 & 10.17 \\
\hline & OMLSA & \multicolumn{6}{|c|}{7.93} \\
\hline
\end{tabular}

محدوده قابهاى انتخابى با توجه به محدوده تُنُكى قابهاى اوليه نوفهاى سيخنال مشاهده شده است. همجنين

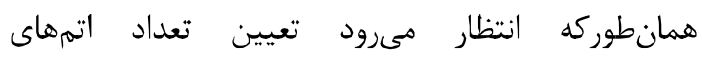
تشكيلدهنده وازهنامه و حذف اتمهاى بازنمايى كننده ويثرَى هاى نوفهاى بسيار حائز اهميت است و بههمين دليل با كمشدن يا زيادشدن بيش از حد مطلوب تعداد اتمها، نتايج بهسازى بهشدت مورد تأثير قرار مى گيرد. كَفتى است كل نتايج بهسازى الكوريته ييشنهادى در حضور نوفه صورتى اندكى بالاتر از نتايج حاصل از كاهش نوفه در مقابل نوفه قهوماى است.

نتايج گزارششده نشان مى مهد كه بهسازى حاصل از الكوريتم GAD و GAD_Gini نزديك به هم و مناسب بوده و در بيشتر موارد بالاتر از الگُوريتم PCA است كه در آن فضاى مسأله به دو زيرفضاى كَتار و نوفه تجزيه مىشود. در برخى شرايط بسته به تعداد اتم بهكارگرفته شده، نتايج حاصل از الكوريتم GAD بالاتر از GAD_Gini بهدست آمده است. كفتنى است كه كارايى الگوريتم يإيين مناسبتر خواهد بود. نتايج SNR GAD_Gini حاصل از بهسازى در حضور نوفههاى صورتى و قهوهاى اندكى هايينتر از نتايج گزارششده از نوفه سفيد گَوسى بوده است كه مي تواند به اين علت باشد كه معيار جينى ريشنهادى بهترين انطباق را بلمنظور اكتساب قابهاى تُنُك براساس نوفه سفيد گُوسى بهدست مى بـهد.
در اين جدول، نتايج حاصل از روش 'OMLSA نيز

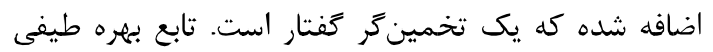
بهينه در اين روش براساس يك ميانگين هندسى وزندار

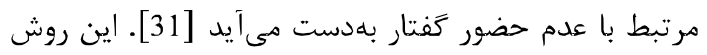
بهمنظور حذف نوفهاي نايستا ارائه شده است. طيف نوفه در اين روش بهكمى ميانگينَيرى بازگشتى توان طيف با

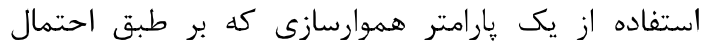
حضور گفتتار تنظيم مىشود، تخمين زده مىشود؛ همجنين

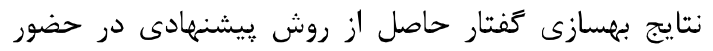
نوفههاى غيركوسى مانند نوفه صورتى و نوفه قهوهاى بهترتيب در جداول (F و ه) كزارش شده است. انجام اين شبيهسازى بdمنظور بررسى كارايى روش ييشنهادى در حضور نوفههاى غيرَّوسى صورت گرفته است. همانطوركه

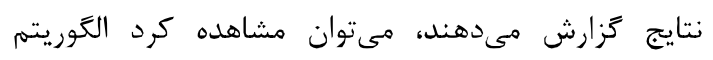
ييشنهادى توانسته است به مقادير ISNR بالاترى در شرايط نوفهاى مختلف نسبت به روشهاى يايه آموزش وازمهامه

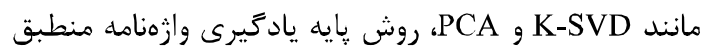
بر داده بهكمك دعيار نرم و نيز روش OMLSA كه يك تخمينكر كَفتارى بلمنظور حذف نوفههاى نايستا است،

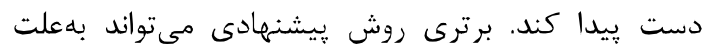
اصلاحات دقيقى باشد كه در روش يايه يادگيرى وازمنامه

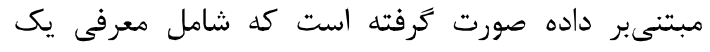

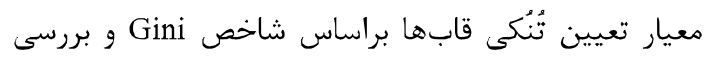

${ }^{1}$ Optimally-modified log-spectral amplitude 
(جدول - F) : نتايج حاصل از معيار ISNR در حضور نوفه صورتى در is

(Table-4): The results of ISNR value in the presence of Pink noise in different SNR values

\begin{tabular}{|c|c|c|c|c|c|c|c|}
\hline \multirow{2}{*}{ SNR } & \multirow{2}{*}{ Method } & \multicolumn{6}{|c|}{ Number of atoms in dictionary } \\
\hline & & 512 & 400 & 300 & 200 & 100 & $\mathbf{5 0}$ \\
\hline \multirow{5}{*}{$-10 \mathrm{~dB}$} & PCA & 0 & 0.41 & 1.32 & 2.21 & 4.49 & 5.63 \\
\hline & K-SVD & 5.12 & 5.82 & 6.21 & 6.03 & 5.10 & 3.96 \\
\hline & $\mathrm{GAD}$ & 0 & 1.14 & 2.81 & 4.20 & 4.82 & 3.85 \\
\hline & GAD Gini & 0 & 2.17 & 3.81 & 4.72 & 4.89 & 4.11 \\
\hline & OMLSA & \multicolumn{6}{|c|}{4.52} \\
\hline \multirow{5}{*}{$0 \mathrm{~dB}$} & PCA & 0 & 0.59 & 1.22 & 2.65 & 5.32 & 8.04 \\
\hline & K-SVD & 5.03 & 6.83 & 7.02 & 7.69 & 8.46 & 9.88 \\
\hline & GAD & 0 & 1.22 & 2.59 & 5.14 & 7.16 & 9.01 \\
\hline & GAD Gini & 0 & 2.36 & 3.47 & 6.35 & 7.95 & 6.93 \\
\hline & OMLSA & \multicolumn{6}{|c|}{6.84} \\
\hline \multirow{5}{*}{$-10 \mathrm{~dB}$} & PCA & 0 & 0.44 & 1.23 & 2.65 & 5.37 & 8.19 \\
\hline & K-SVD & 4.92 & 6.68 & 7.47 & 9.85 & 12.39 & 13.41 \\
\hline & GAD & 0 & 1.22 & 2.71 & 5.19 & 7.52 & 9.18 \\
\hline & GAD Gini & 0 & 1.43 & 2.96 & 6.43 & 8.16 & 9.86 \\
\hline & OMLSA & \multicolumn{6}{|c|}{7.18} \\
\hline
\end{tabular}

(جدول - (D): نتايج حاصل از معيار ISNR در حضور نوفه قهوهاى در SNNR

(Table-5): The results of ISNR value in the presence of Brown noise in different SNR values

\begin{tabular}{|c|c|c|c|c|c|c|c|}
\hline \multirow{2}{*}{ SNR } & \multirow{2}{*}{ Method } & \multicolumn{6}{|c|}{ Number of atoms in dictionary } \\
\hline & & 512 & 400 & 300 & 200 & 100 & 50 \\
\hline \multirow{5}{*}{$-10 \mathrm{~dB}$} & PCA & 0 & 0.38 & 1.29 & 2.17 & 4.42 & 5.55 \\
\hline & K-SVD & 5.08 & 5.73 & 6.15 & 5.89 & 5.03 & 3.89 \\
\hline & GAD & 0 & 1.08 & 2.75 & 4.15 & 4.81 & 3.80 \\
\hline & GAD Gini & 0 & 2.14 & 3.76 & 4.65 & 4.81 & 4.05 \\
\hline & OMLSA & \multicolumn{6}{|c|}{4.42} \\
\hline \multirow{5}{*}{$0 \mathrm{~dB}$} & PCA & 0 & 0.52 & 1.18 & 2.60 & 5.31 & 7.96 \\
\hline & K-SVD & 4.95 & 6.75 & 6.92 & 7.61 & 8.45 & 9.82 \\
\hline & GAD & 0 & 1.18 & 2.51 & 5.06 & 7.08 & 8.92 \\
\hline & GAD_Gini & 0 & 2.29 & 3.41 & 6.28 & 7.91 & 6.90 \\
\hline & OMLSA & \multicolumn{6}{|c|}{6.77} \\
\hline \multirow{5}{*}{$-10 \mathrm{~dB}$} & PCA & 0 & 0.39 & 1.14 & 2.72 & 5.34 & 8.16 \\
\hline & K-SVD & 4.88 & 6.64 & 7.42 & 9.81 & 12.36 & 13.38 \\
\hline & $\mathrm{GAD}$ & 0 & 1.20 & 2.67 & 5.12 & 7.49 & 9.15 \\
\hline & GAD Gini & 0 & 1.38 & 2.91 & 6.59 & 8.11 & 9.81 \\
\hline & OMLSA & \multicolumn{6}{|c|}{7.14} \\
\hline
\end{tabular}

ييشنهلادى در حضور نوفههاى غير گوسى گزارش شده است.

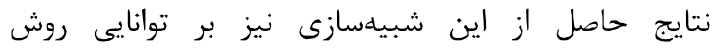
ييشنهادى در حذف نوفههاى غيركوسى از سيخنال كفتار

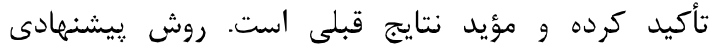
توانسته در شرايط نوفهاى مختلف، مقادير PESQ بالاترى

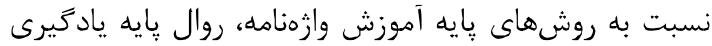
وازمنامه منطبق بر داده و نيز روش OMLSA بدست دهد كه

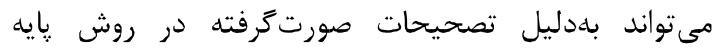
ياد كيرى وازثنامله مبتنىعبر داده باشد كه در بخش بـ به به آنها

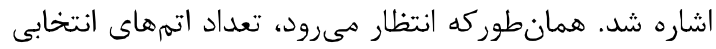

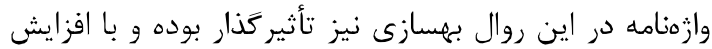

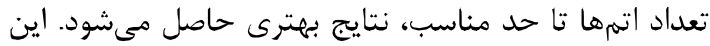

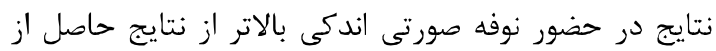
كاهش نوفه در مقابل نوفه قهوهاى حاصل شده است؛ همجنين نتايج الكوريتم بيشنهادى بهكمك اعمال محدوده

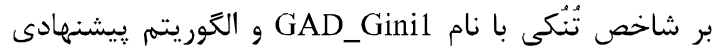

همجنين نتايج بهسازى بلدستآمده با استفاده از معيار 'PESQ، از آنجاييكه همدوسى بالايى با امتيازهاى بهاى حاصل از معيارهاى قابليت فهزم و كيفيت كَفتار دارد، محاسبه شده است [32]. در اين آزمايش از برنامههاى آماده در نرمافزار متلب' كه در [32] ارائه شده، استفاده شده است. نتايج حاصل از اين معيار به منظور بهسازى سيخنال در دران حضور نوفه سفيد گَوسى با SNR (9اى مختلف در جدول

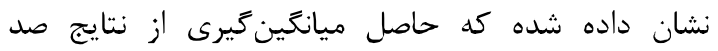
سيخنال كفتارى است. همانطوركه انتظار مىرود با كاهش تعداد اتمها در وازمنامه، خطاى بازسازى بيشتر و هعيار كاهش مى يابد؛ همجنين نتايج معيار PESQ

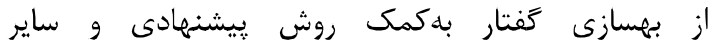

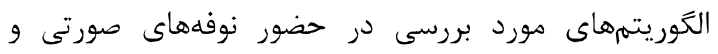
قهوهاى بهترتيب در جداول (V و A) كزارش شده است. نتايج حاصل از معيار PESQ بهمنظور بر رسى تكميلى كارايى روش

${ }^{1}$ Perceptual evaluation of speech quality ${ }^{2}$ MATLAB 
بهكمك روش بيشنهادى در (1) نهاى مختلف در شكل

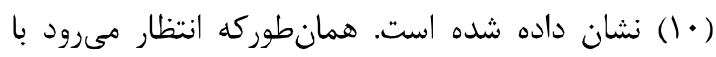
افزايش ميزان SNR، نتايج بهترى بهدست مى آيد؛ همجِنين

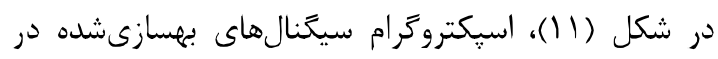

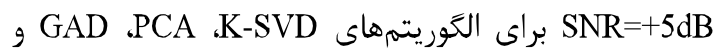
GAD_Gini

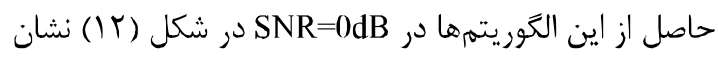
داده شده است. نتايج حاصل نشان مىدهد كه الكوريتم

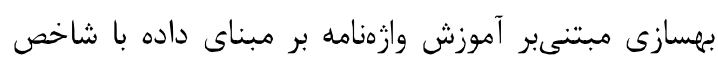

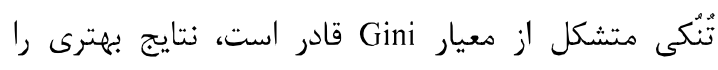

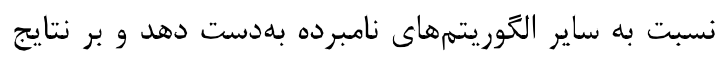

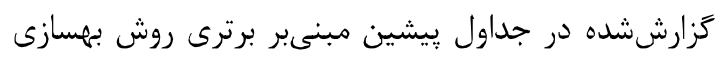
بيشنهادى تأكيد دارد.

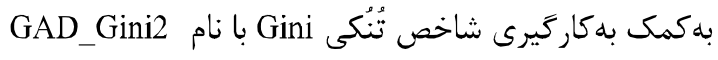

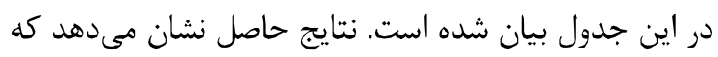

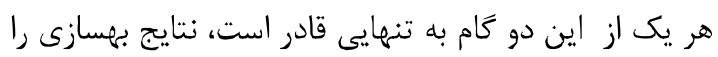

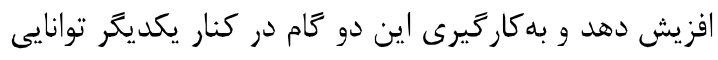

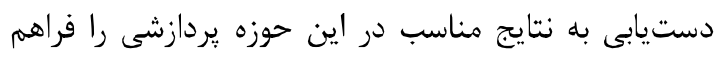

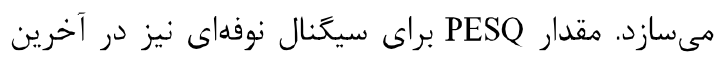

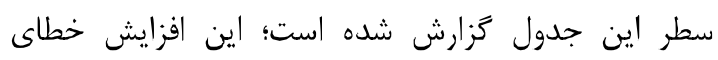

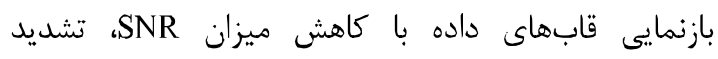

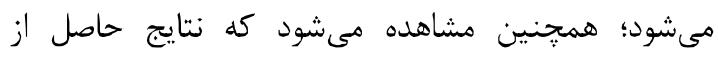

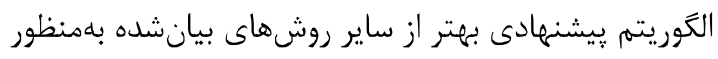

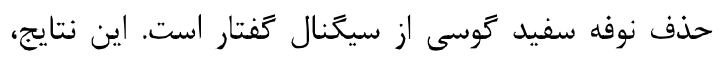

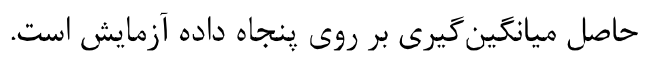

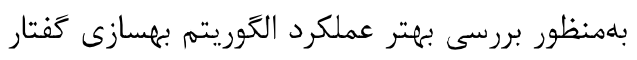

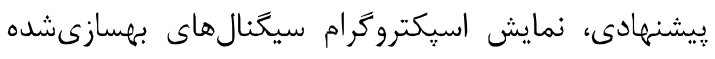

(جدول -9): نتايج حاصل از معيار PESQ در حضور نوفه سفيد گوسى و در SNR

(Table-6): The results of PESQ values in the presence of white Gaussian noise in different SNR values for various numbers of atoms

\begin{tabular}{|c|c|c|c|c|c|c|c|c|c|}
\hline \multirow{2}{*}{$\begin{array}{ll}\mathrm{SNR} \rightarrow & \text { Methods } \downarrow \\
\end{array}$} & \multicolumn{3}{|c|}{$-10 \mathrm{~dB}$} & \multicolumn{3}{|c|}{$0 \mathrm{~dB}$} & \multicolumn{3}{|c|}{$+10 \mathrm{~dB}$} \\
\hline & 512 & 300 & 100 & 512 & 300 & 100 & 512 & 300 & 100 \\
\hline PCA & 0.76 & 0.42 & 0.23 & 2.61 & 1.98 & 0.93 & 3.56 & 2.88 & 2.04 \\
\hline K-SVD & 1.06 & 0.79 & 0.73 & 2.78 & 2.37 & 1.12 & 3.70 & 2.96 & 2.26 \\
\hline OMLSA & \multicolumn{3}{|c|}{0.15} & \multicolumn{3}{|c|}{0.76} & \multicolumn{3}{|c|}{2.53} \\
\hline GAD & 1.59 & 1.28 & 0.80 & 3.03 & 2.54 & 1.67 & 3.75 & 3.09 & 2.39 \\
\hline GAD Ginil & 1.61 & 1.32 & 0.83 & 3.09 & 2.57 & 1.70 & 3.77 & 3.14 & 2.41 \\
\hline GAD Gini2 & 1.63 & 1.35 & 0.85 & 3.12 & 2.59 & 1.73 & 2.81 & 3.17 & 2.45 \\
\hline GAD Gini & 1.65 & 1.39 & 0.87 & 3.17 & 2.61 & 1.78 & 3.84 & 3.21 & 2.48 \\
\hline Noisy signal & \multicolumn{3}{|c|}{0.18} & \multicolumn{3}{|c|}{0.88} & \multicolumn{3}{|c|}{1.86} \\
\hline
\end{tabular}

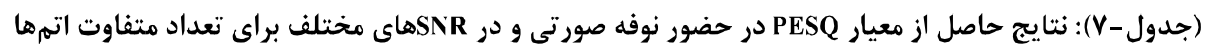

(Table-7): The results of PESQ values in the presence of Pink noise in different SNR values for various numbers of atoms

\begin{tabular}{|c|c|c|c|c|c|c|c|c|c|}
\hline \multirow{2}{*}{$\begin{array}{l}\text { SNR } \rightarrow \quad \text { Methods } \downarrow \\
\end{array}$} & \multicolumn{3}{|c|}{$-10 \mathrm{~dB}$} & \multicolumn{3}{|c|}{$0 \mathrm{~dB}$} & \multicolumn{3}{|c|}{$+10 \mathrm{~dB}$} \\
\hline & 512 & $\mathbf{3 0 0}$ & 100 & 512 & 300 & 100 & 512 & $\mathbf{3 0 0}$ & 100 \\
\hline PCA & 0.73 & 0.40 & 0.22 & 2.59 & 1.95 & 0.91 & 3.52 & 2.81 & 1.98 \\
\hline K-SVD & 1.02 & 0.78 & 0.71 & 2.75 & 2.38 & 1.09 & 3.66 & 2.93 & 2.21 \\
\hline OMLSA & \multicolumn{3}{|c|}{0.13} & \multicolumn{3}{|c|}{0.73} & \multicolumn{3}{|c|}{2.49} \\
\hline GAD & 1.53 & 1.25 & 0.77 & 3.05 & 2.51 & 1.70 & 3.72 & 3.01 & 2.34 \\
\hline GAD Ginil & 1.57 & 1.29 & 0.79 & 3.04 & 2.58 & 1.73 & 3.75 & 3.12 & 2.38 \\
\hline GAD Gini2 & 1.61 & 1.32 & 0.80 & 3.09 & 2.55 & 1.71 & 2.78 & 3.15 & 2.39 \\
\hline GAD Gini & 1.66 & 1.37 & 0.85 & 3.15 & 2.63 & 1.76 & 3.82 & 3.19 & 2.45 \\
\hline Noisy signal & \multicolumn{3}{|c|}{0.17} & \multicolumn{3}{|c|}{0.83} & \multicolumn{3}{|c|}{1.85} \\
\hline
\end{tabular}

(جدول-1): نتايج حاصل از معيار PESQ در حضور نوفه قهوهاى و در SDNR

(Table-8): The results of PESQ values in the presence of Brown noise in different SNR values for various numbers of atoms

\begin{tabular}{|c|c|c|c|c|c|c|c|c|c|}
\hline \multirow{2}{*}{ 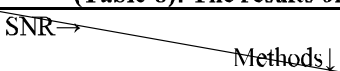 } & \multicolumn{3}{|c|}{$-10 \mathrm{~dB}$} & \multicolumn{3}{|c|}{$0 \mathrm{~dB}$} & \multicolumn{3}{|c|}{$110 \mathrm{~dB}$} \\
\hline & 512 & 300 & 100 & 512 & 300 & 100 & 512 & 300 & 100 \\
\hline PCA & 0.68 & 0.35 & 0.18 & 2.50 & 1.89 & 0.87 & 3.46 & 2.77 & 1.91 \\
\hline K-SVD & 0.96 & 0.71 & 0.65 & 2.71 & 2.31 & 0.98 & 3.59 & 2.88 & 2.18 \\
\hline OMLS $\Lambda$ & \multicolumn{3}{|c|}{0.11} & \multicolumn{3}{|c|}{0.67} & \multicolumn{3}{|c|}{2.42} \\
\hline GAD & 1.49 & 1.21 & 0.72 & 2.98 & 2.47 & 1.66 & 3.67 & 2.94 & 2.28 \\
\hline GAD_Ginil & 1.51 & 1.23 & 0.73 & 2.96 & 2.49 & 1.67 & 3.69 & 3.04 & 2.31 \\
\hline GAD Gini2 & 1.55 & 1.27 & 0.76 & 3.01 & 2.49 & 1.68 & 2.73 & 3.07 & 2.31 \\
\hline GAD Gini & 1.61 & 1.31 & 0.79 & 3.09 & 2.58 & 1.70 & 3.78 & 3.14 & 2.39 \\
\hline Noisy signal & \multicolumn{3}{|c|}{0.19} & \multicolumn{3}{|c|}{0.81} & \multicolumn{3}{|c|}{1.79} \\
\hline
\end{tabular}




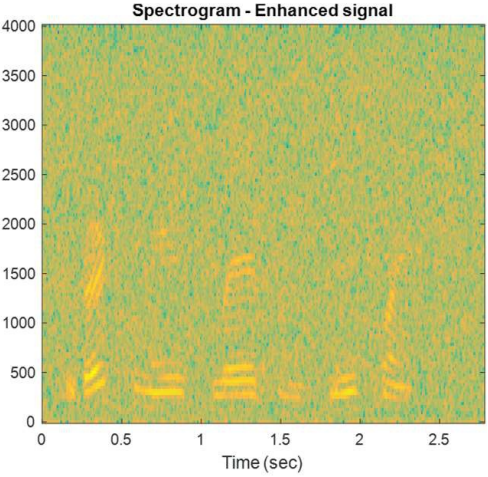

(c)

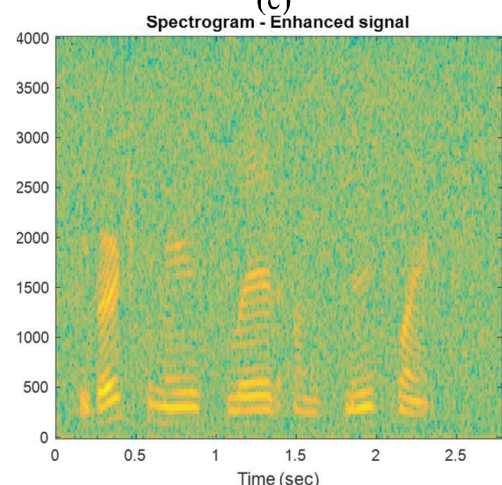

(f)

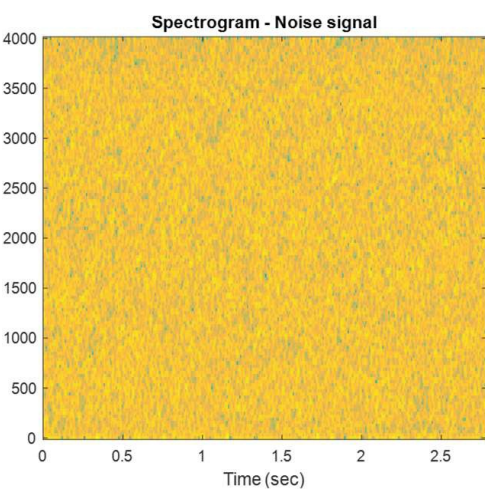

(b)

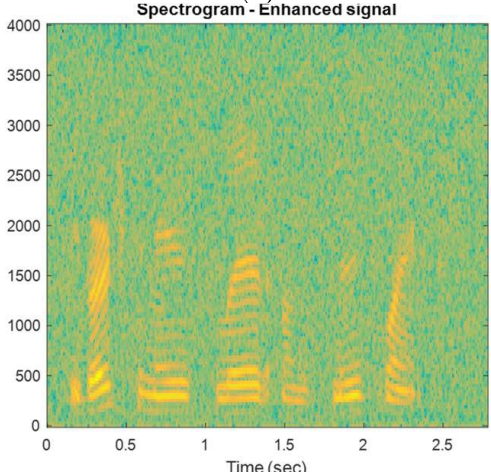

(e)

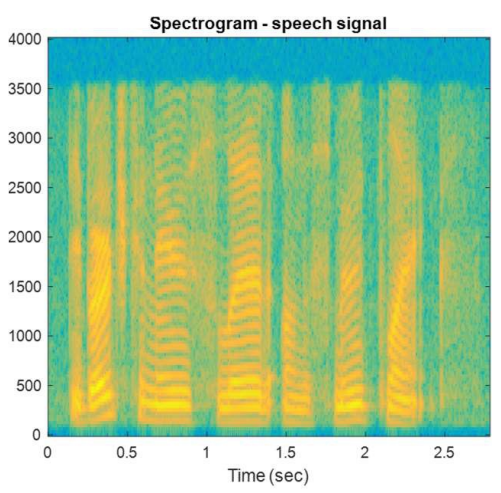

(a)

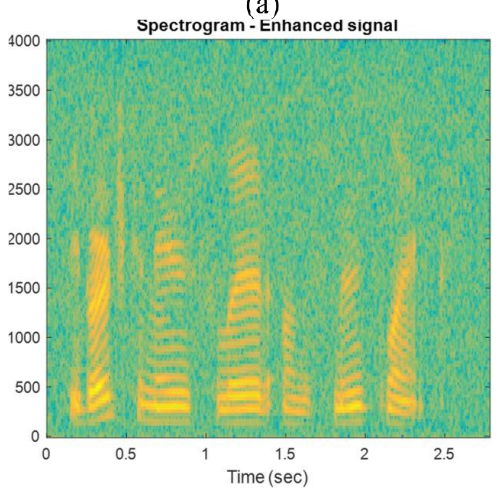

(d)

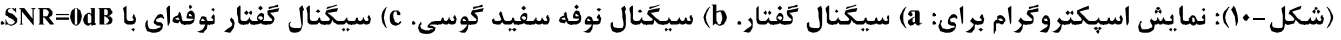

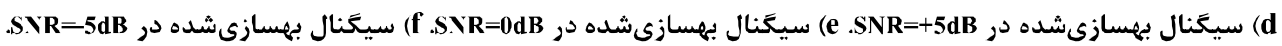

(Figure-10): Spectrogram representation for: a) Speech signal. b) Gaussian white noise signal. c) Noisy signal. d) Enhanced signal at $\mathrm{SNR}=+5 \mathrm{~dB}$. e) Enhanced signal at $\mathrm{SNR}=0 \mathrm{~dB}$. f) Enhanced signal at $\mathrm{SNR}=-5 \mathrm{~dB}$.
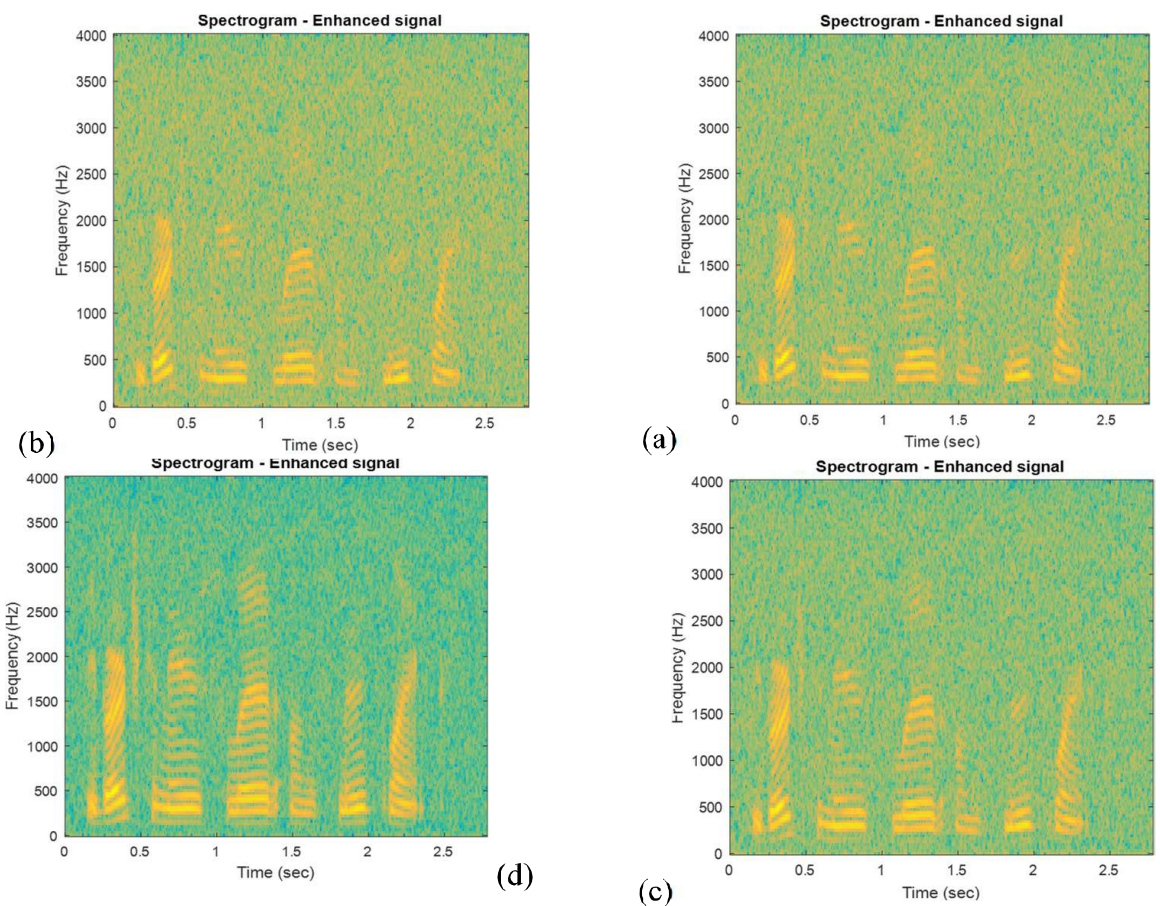

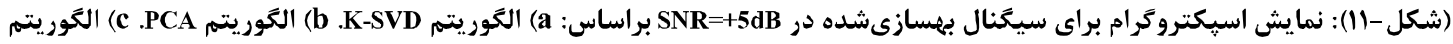
.GAD_Gini الكوريتم

(Figure-11): Spectrogram representation for the enhanced signal at SNR=+5dB using: a) K-SVD algorithm. b) PCA algorithm. c) GAD algorithm. d) GAD_Gini algorithm. 

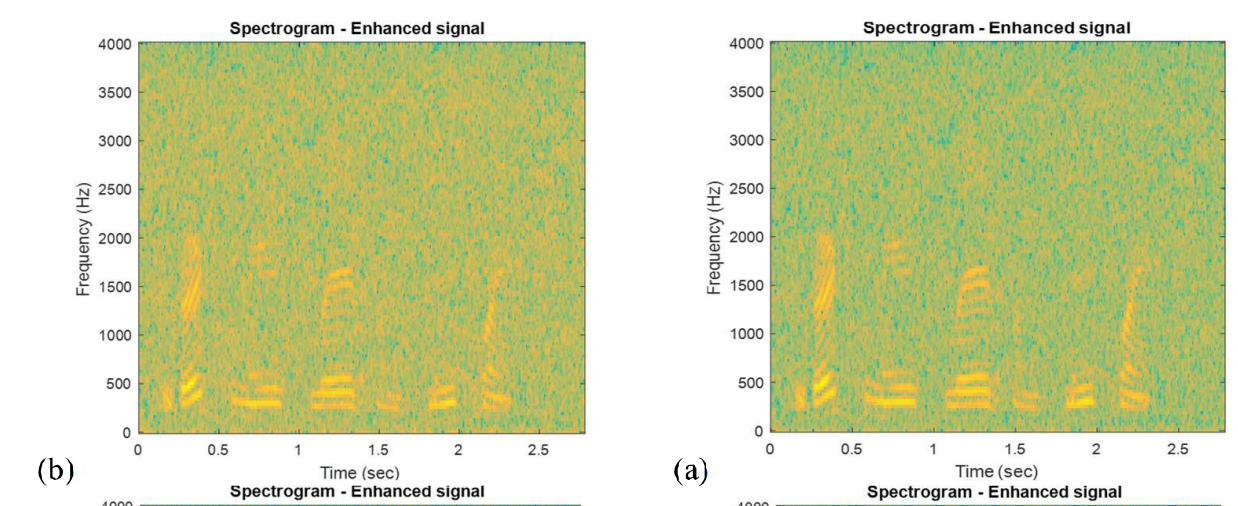

(d)
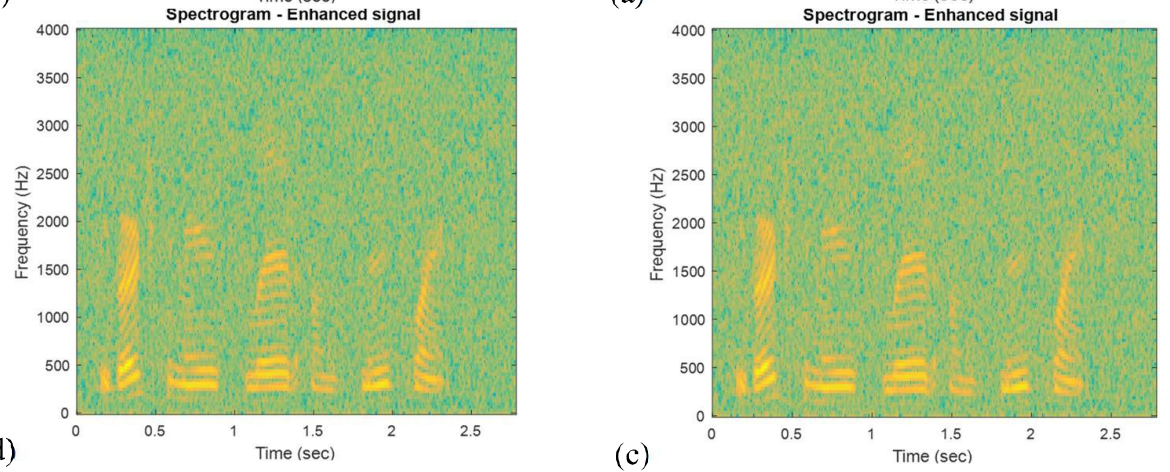

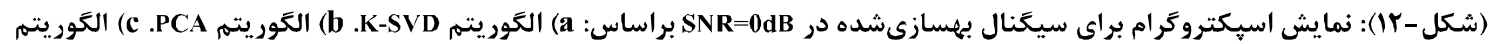

a الخوريتم (d .GAD

(Figure-12): Spectrogram representation for the enhanced signal at SNR=0dB using: a) K-SVD algorithm. b) PCA algorithm. c) GAD algorithm. d) GAD_Gini.

\section{ه- نتيجه كيرى}

در اين مقاله روشهاى يادكيرى وازّهامه مبتنىبر داده معرفى شد. از اين ميان روش يادكيرى وازثنامه تطبيقى

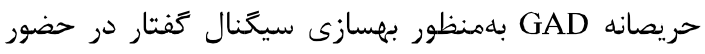
نوفه سفيد كوسى مورد توجه قرار ترفت. وازهنامه در اين روش بلهور مستقيم از روى سيكنال كفتار يادكيرى مىشود تا تطابق بيشترى ميان اتمها و ساختار سيخنال

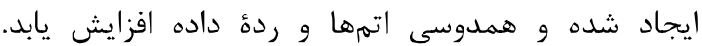

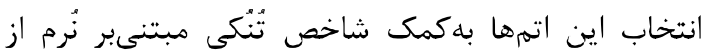

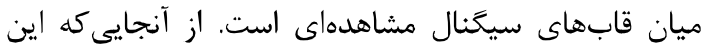

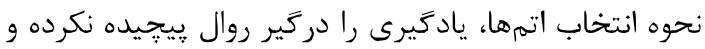
سرعت هم كرايى بالايى بلهدست مىدهد، بر آن شديم تا با با ديا

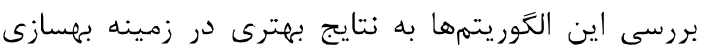

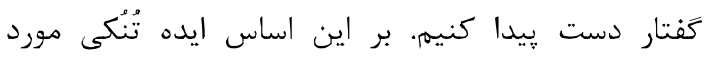
بررسى قرار گرفت و بر مبناى معيارهاى مطرحشده براى

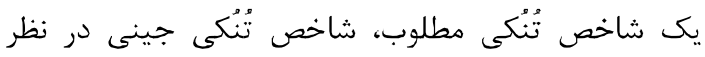

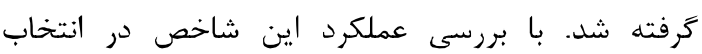
قابهاى داده به اين نتيجه رسيديم كه عملكرد اين شاخص برد

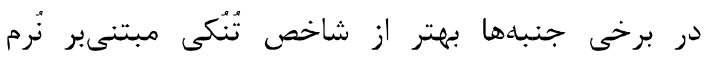

همجنين، زمان محاسباتى براى اجراى روشهاى

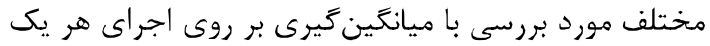

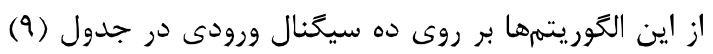

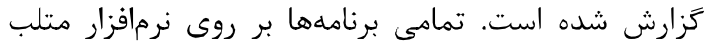
Core i5 $3.2 \mathrm{GHz}$ براساس ويندوز اجرا شده است. همانطور كه ديده ميشود، زمان روال اجراى روش پيشنهادى بهعلت مرتبكردن ضرايب و و

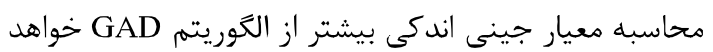
بود. الكوريتم K-SVD بهعلت بهكار كيرى روال تكرارشونده بلمنظور همثرايى به كمترين خطاى تقريب، زمان اجراى

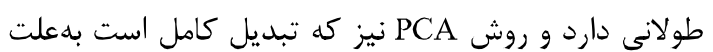

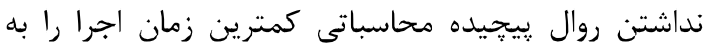

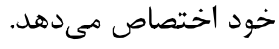

(جدول-9): ميانكين زمان محاسباتى براى اجراى روشهاى

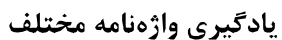

(Table-9): The average of computation time for dictionary

\begin{tabular}{|c|c|}
\hline \multicolumn{2}{|c|}{ learning of different methods } \\
\hline 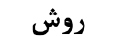 & ميانغين زمان اجرا (ثانيه) \\
\hline PC $\Lambda$ & 10 \\
\hline K-SVD & 6744 \\
\hline GAD & 173 \\
\hline GAD-Gini & 178 \\
\hline
\end{tabular}


information", IEEE Trans. Inform. Theory, vol. 52, No. 2, pp. 489-509, 2006.

[10] E. J. Candes, T. Tao, "Near-optimal signal recovery from random projections and universal encoding strategies", IEEE Trans. Inform. Theory, vol. 52, No. 12, pp. 54065425, 2006.

[11] H. Xu, "Speech enhancement based on compressed sensing technology", Sensors \& Transducers Journal, vol. 181, pp. 141-145, 2014.

[12] G. S. Sivaram, S. K. Nemala, M. Elhilali, H. Hermansky, "Sparse coding for speech recognition", IEEE International Conference on Acoustics Speech and Signal Processing (ICASSP), pp. 4346-4349, 2010.

[13] D. D. Lee, H. S. Seung, "Learning the parts of objects by non-negative matrix factorization", Nature 401, 788- 791, 1999.

[14] N. Mohammadiha, P. Smaragdis, A. Lcijon, "Supervised and unsupervised speech enhancement using nonnegative matrix factorization", IEEE Transactions on Audio, Speech, and Language Processing, vol. 21, No. 10, pp.2140-2151, 2013.

[15] J. T. Geiger, J. F. Gemmeke, B. Schuller, and G. Rigoll, "Investigating NMF speech enhancement for neural network based acoustic models", Proceedings of the Annual Conference of International Speech Communication Association (INTERSPEECH), 2014.

[16] P. O. Hoyer, "Non-negative matrix factorization with sparseness constraints", J. Mach. Learn. Res., vol. 5, pp. 1457-1469, 2004.

[17] C. D. Sigg, T. Dikk, J. M. Buhmann, "Speech enhancement with sparse coding in learned dictionaries", In Acoustics Speech and Signal Processing (ICASSP), IEEE International Conference on, pp. 4758-4761, 2010.

[18] C. D. Sigg, T. Dikk, J. M. Buhmann, "Speech enhancement using generative dictionary lcarning", IEEE Transactions on Audio, Speech, and Language Processing, vol. 20, No. 6, pp. 1698-1712, 2012.

[19] M. Aharon, M. Elad, A. Bruckstein, "K-SVD: An algorithm for designing overcomplete dictionaries for sparse representation", IEEE Trans. Signal Process, vol. 54, No. 11, pp. 4311-4322, 2006.

[20] H. Yongjun, J. Han, S. Deng, T. Zheng, G. Zheng, "A solution to residual noise in speech denoising with sparse representation", In Acoustics, Specch and Signal Processing
دعرفىشده، خواهد بود. بنابراين اين شاخص در روال الكوريتهم يادكيرى وازهنامه تطبيقى حريصانه مورد استفاده قرار گرفت. نتايج حاصل از شبيهسازىهاى مختلف نشان مى دهد كه اترجه شاخص بيشنهادى در تمامى شرايط

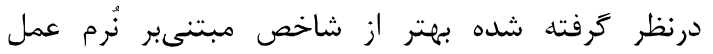

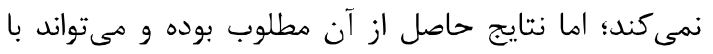
دقت مناسبى در بهسازى كفتار مورد استفاده قرار گيرد.

\section{6- References}

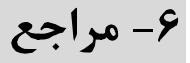

[1] H. Guo, B. Zhao, G. Zhou, "Image compression based on compressed sensing theory and wavelet packet analysis", Cross Strait Quad-Regional Radio Science and Wireless Technology Conference, vol. 2, pp. 1426-1429, 2011.

[2] J. L. Starck, M. Elad, D. L. Donoho, "Image decomposition via the combination of sparse representation and a variational approach", IEEE Trans. on Image Proces, vol. 14, No. 10, pp. 1570-1582, 2005.

[3] F. Rodriguez, G. Sapiro, "Sparse representation for image classification: Learning discriminative and reconstructive non-parametric dictionaries", IMA Preprint, 2007.

[4] S. Zhang, J. Huang, D. Metaxas, W. Wang, X. Huang, "Discriminative sparse representations for cervigram image segmentation", IEEE International Symposium on Biomedical Imaging: From Nano to Macro, pp.133-136, 2010.

[5] M. S. Lewiki, T. J. Sejnowski, "Learning overcomplete representations", Neural Computing, vol. 12, No. 2, pp. 337-365, 2000.

[6] D. Giacobello, M. G. Christensen, M. N. Murthi, S. H. Jensen, M. Moonen, "Retrieving sparse patterns using a compressed sensing framework: applications to speech coding based on sparse lincar prediction", IEEE Signal Processing Letters, vol. 17, No. 1, pp.103-106, 2010.

[7] D. Wu, Z. Ping, M. N. S. Swamy, "A compressive sensing method for noise reduction of specch and audio signals", IEEE 54th International Midwest Symposium on Circuits and Systems, pp. 1-4, 2011.

[8] D. Wu, Z.W. Ping, M. N. S. Swamy, "On sparsity issues in compressive sensing based speech enhancement", IEEE International Symposium on Circuits and Systems, pp. 285288, 2012.

[9] E. Candès, J. Romberg, T. Tao, "Robust uncertainty principles: exact signal reconstruction from highly incomplete frequency 


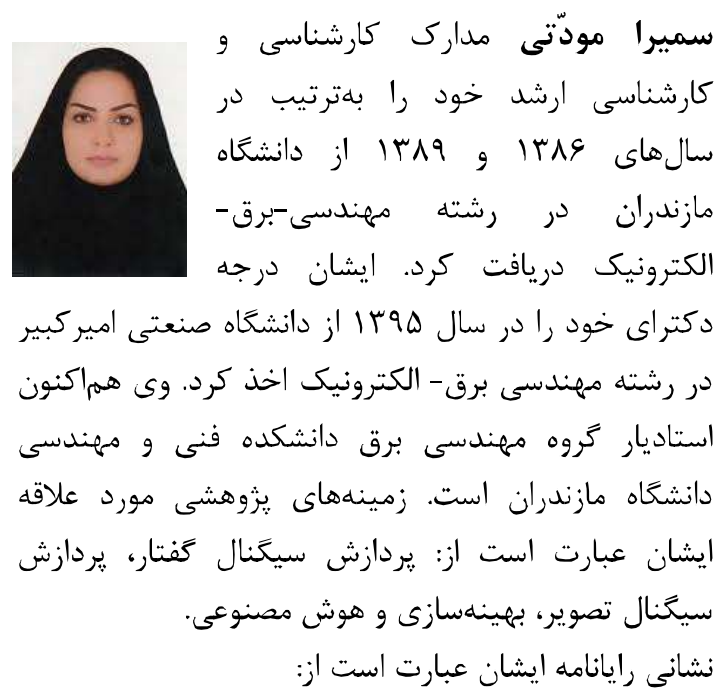

s.mavaddati@umz.ac.ir

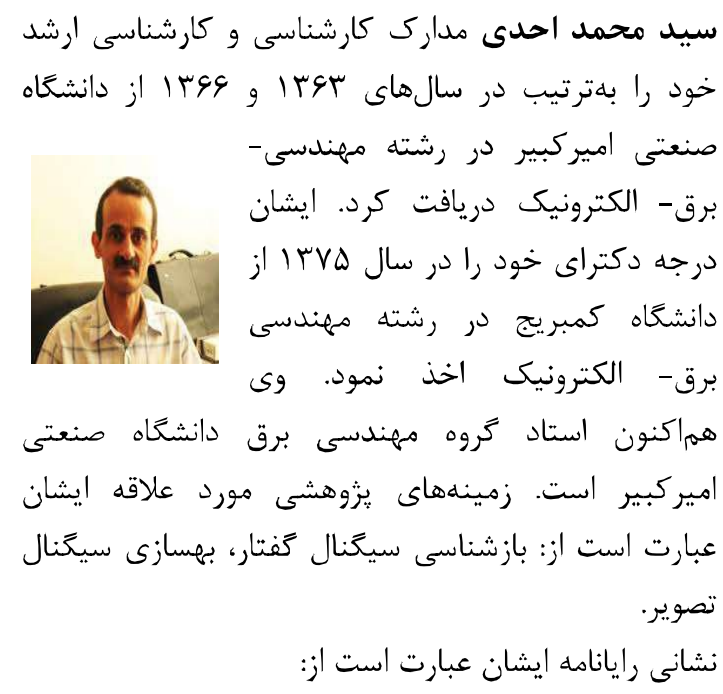

sma@aut.ac.ir
(ICASSP), IEEE International Conference on, pp. 4653-4656, 2012.

[21] S. Mavaddaty, S. M. Ahadi, S. Seyedin, "A novel speech enhancement method by learnable sparse and low-rank decomposition and domain adaptation", Speech Communication, vol. 76, pp. 42-60, 2016.

[22] M. G. Jafari, M. D. Plumbley, "Speech denoising based on a greedy adaptive dictionary algorithm", 17th European Signal Processing Conference (EUSIPCO), pp. 14231426, 2009.

[23] M. G. Jafari, M. D. Plumbley, "Fast dictionary learning for sparse representations of speech signals", IEEE Journal of selected topics in signal processing, vol. 5, pp. 1025-1031, 2011.

[24] R. Rubinstein, M. Zibulevsky, M. Elad, "Double sparsity: Learning sparse dictionaries for sparse signal approximation", IEEE Trans. on Signal Processing, Vol. 58, pp. 1553-1564, 2010.

[25] M. G. Jafari, E. Vincent, S. A. Abdallah, M. D. Plumbley, M. E. Davies, "An adaptive stereo basis method for convolutive blind audio source separation", Neuro computing, vol. 71, pp. 2087-2097, 2008.

[26] http://www.dcs.shef.ac.uk/spandh/gridcorpus.

[27] N. Hurley, S. Rickard, "Comparing measures of sparsity", IEEE Trans. on Information Theory, vol. 55, pp. 4723-4741, 2009.

[28] S. Rickard, M. Fallon, "The gini index of speech", In Proc. Of Information Sciences and Systems conference, Princeton, NJ, 2004.

[29] P. J. Wolfe, "Sparse time-frequency representations in audio processing, as studied through a symmetrized lognormal model," In Proc. of the European Signal Processing Conference (EUSIPCO), pp. 355-359, 2007.

[30] H. Dalton, "The measurement of the inequity of incomes", Economic Journal, Vol. 30, pp. 348$361,1920$.

[31] I. Cohen, B. Berdugo, "Speech enhancement for non-stationary noise environments", Signal processing, vol. 81, No. 11, pp. 2403-2418, 2001.

[32] A. Rix, J. Becrends, M. Hollier, A. Hekstra, "Perceptual evaluation of speech quality (PESQ)-a new method for speech quality assessment of telephone networks and codecs", In Proc. IEEE Int. Conf. Acoustics, Speech, Signal Process., pp. 749-752, 2001. 